\title{
Self-Potential Observations During Hydraulic Fracturing
}

Jeffrey R. Moore

Steven D. Glaser

University of California, Berkeley

Lawrence Berkeley National Laboratory

Department of Civil and Environmental Engineering

760 Davis Hall

Berkeley, CA USA

E-mail: moore@ce.berkeley.edu

\begin{abstract}
The self-potential (SP) response during hydraulic fracturing of intact Sierra granite was investigated in the laboratory. Excellent correlation of pressure drop and SP suggests that the SP response is created primarily by electrokinetic coupling. For low pressures, the variation of SP with pressure drop is linear, indicating a constant coupling coefficient $(\mathrm{Cc})$ of $-200 \mathrm{mV} / \mathrm{MPa}$. However for pressure drops $>2 \mathrm{MPa}$, the magnitude of the $\mathrm{Cc}$ increases by $80 \%$ in an exponential trend. This increasing $\mathrm{Cc}$ is related to increasing permeability at high pore pressures caused by dilatancy of micro-cracks, and is explained by a decrease in the hydraulic tortuosity. Resistivity measurements reveal a decrease of $2 \%$ prior to hydraulic fracturing and a decrease of $\sim 35 \%$ after fracturing. An asymmetric spatial SP response created by injectate diffusion into dilatant zones is observed prior to hydraulic fracturing, and in most cases this SP variation revealed the impending crack geometry seconds before failure. At rupture, injectate rushes into the new fracture area where the zeta potential is different than in the rock porosity, and an anomalous SP spike is observed. After fracturing, the spatial SP distribution reveals the direction of fracture propagation. Finally, during tensile cracking in a point load device with no water flow, a SP spike is observed that is caused by contact electrification. However, the time constant of this event is much less than that for transients observed during hydraulic fracturing, suggesting that SP created solely from material fracture does not contribute to the SP response during hydraulic fracturing.
\end{abstract}

\section{Introduction}

Hydraulic fracturing creates a network of tensile fractures in low-permeability reservoir rock by introducing high fluid pressures at depth in a borehole. Permeability 
enhancement is critical for oil and gas extraction, and for the creation of a heatexchanging circulation zone for hot dry rock geothermal power generation. Fracture orientation is generally controlled by the regional stress field, with the fracture propagating in the direction of the maximum compressive principal stress.

The self-potential (SP) method is a passive geophysical tool which measures naturally occurring voltages created by fluid flow through geologic materials. The SP response during compression of saturated intact rock specimens is well documented (Jouniaux and Pozzi, 1995; Lorne et al., 1999b; Yoshida, 2001; Eccles et al., 2005). Researchers have noted an anomalous change in the SP response beginning at about $75 \%$ of the failure load, which may be related to the onset of dilatancy. In related testing, electrical resistivity variations in rock samples have been characterized during frictional sliding and compression, and an anomalous decrease is observed preceding failure (Wang et al., 1978; Lockner and Byerlee, 1986; Chen and Lin, 2004). These results support the hypothesis that earth materials undergo dilatancy prior to failure and local pore water diffuses into the low-pressure dilatant zone (Scholz et al., 1973).

To explain electrical phenomena accompanying earthquakes, Mizutani et al. (1976) proposed that migrating pore waters may create anomalous SP via electrokinetic coupling. Yoshida et al. (1998) then demonstrated that there was no SP response during deformation in dry basalt specimens, whereas there was a considerable SP response for saturated basalt specimens. This provided evidence that observed self-potentials result from electrokinetic coupling. Much related research has been conducted with the goal of interpreting electromagnetic anomalies that precede and accompany fault rupture (e.g. Corwin and Morrison, 1977; Fitterman, 1978; Gokhberg et al., 1982; Warwick et al., 1982; Lockner et al., 1983; Miyakoshi, 1986; Fenoglio et al., 1995; Varotsos et al., 1999).

We find little information, however, regarding the electrical response during tensile fracturing of earth materials, and even less regarding hydraulic fracturing. Wurmstich (1995) showed numerical results suggesting that the process of hydraulic fracturing augments the SP signal by up to an order of magnitude. He indicated that laboratory experiments were performed, but did not reference these experiments or describe their results. Pritchett and Ishido (2005) recently performed numerical simulations concluding that large SP anomalies are created during hydraulic fracturing 
which could be detected by downhole monitoring. Revil et al. (2003) presented analytical solutions for electrical anomalies created by thermohydromechanical disturbances in the context of hydrothermal circulation in an active volcanic system. They described transient SP signals generated when hydraulic fracturing connects compartmentalized aquifers of varying fluid pressures and releases hydromechanical shock waves, demonstrating that significant surface anomalies can be expected. Greenfield et al. (1977) and Ushijima et al. (1999) both employed an active-source field method where current is introduced via a conductive well casing and potentials are observed on a spatial grid. These authors reported varying levels of success: Greenfield et al. could not identify fracture geometry, while Ushijima et al. successfully resolved the fracture geometry in multiple scenarios. Grinat et al. (2004) monitored the surface SP response during field stimulations at a depth of $3790 \mathrm{~m}$, but observed no correlation between the SP anomalies and injection events. Finally, Kawakami and Takasugi (1994) and Marquis et al. (2002) reported surface SP data during hydraulic stimulation of deep hot dry rock reservoirs, demonstrating good correlation between temporal SP variation and injection pressure and flow rate. Surface anomalies up to $40 \mathrm{mV}$ correlated to both injection and flow-back events. Kawakami and Takasugi (1994) also reported the spatial surface SP variation, but did not mention the orientation of the induced fracture, or whether a correlation to fracture geometry was evident.

We have undertaken a research program to monitor the spatial and temporal SP response during hydraulic fracturing in the laboratory, and to investigate the origins of these signals.

\section{Electrokinetic Phenomena}

Electrokinetic phenomena are made possible by an electric double layer present at the interface between a solid and a liquid phase. Since most minerals have a net negative surface charge, cations from the pore fluid are attracted to this interface. The simplest model of the electric double layer consists of a zone nearest the solid phase where charge is bound to the mineral grain, and a zone of mobile charge that decays to neutral concentration moving away from the grain surface. (For a more detailed description see Ishido and Mizutani, 1981; Morgan et al., 1989; Lorne et al., 1999a; Revil et al., 1999; 
Leroy and Revil, 2004.) Under a pore pressure gradient this charge may be convected with the moving fluid causing a charge imbalance and an electric field. Similarly, if an electric field is applied across a specimen, moving ions in fluid-filled pore throats can create a pressure gradient, a phenomenon labeled electro-osmosis.

The laws controlling linear transport in porous media in the presence of electrokinetic coupling are (Pride, 1994):

$$
\begin{aligned}
& \boldsymbol{q}=-L_{11} \nabla p-L_{12} \nabla \varphi \\
& \boldsymbol{j}=-L_{21} \nabla p-L_{22} \nabla \varphi
\end{aligned}
$$

where $\boldsymbol{q}$ is the volumetric fluid flow density, $\boldsymbol{j}$ is the electric current density, $p$ is the fluid pressure, and $\varphi$ is the electric potential. When the double layer thickness is much smaller than a typical grain surface, the transport coefficients are:

$$
\begin{aligned}
& L_{11}=\frac{k}{\eta} \\
& L_{12}=L_{21}=-\frac{\varepsilon \zeta}{\eta F_{o}} \\
& L_{22}=\sigma_{b}
\end{aligned}
$$

Here $k$ is the fluid-flow permeability, $\eta$ is the dynamic fluid viscosity, $\varepsilon$ is the (absolute) dielectric constant of the fluid, $\sigma_{b}$ is the bulk sample conductivity, $F_{o}$ is the electrical formation factor (a pore topology term), and $\zeta$ is the zeta potential, or the potential on the shear plane separating the mobile and bound charge zones of the double layer. The first term on the right-hand side of Equation (1) is Darcy's Law, the second term of Equation (2) is Ohm's Law, and the remaining terms represent the coupled electrokinetic effect with $L_{12}=L_{21}$ (Onsager, 1931). The second term on the right-hand side of Equation (1) is often neglected since $L_{11} \nabla p>>L_{12} \nabla \varphi$ (Nourbehecht, 1963).

Fluid flow in pore throats causes hydrated cations to be convected relative to the bound charge on the mineral grain surfaces; charge motion known as the convection current. As this charge is deposited in the direction of flow and the bound charge is left exposed at the flow source, a charge separation exists which drives an Ohmic return current, or the conduction current. In the absence of external current sources $(\boldsymbol{j}=0)$, the 
convection current $\left(L_{21} \nabla p\right)$ and conduction current $\left(L_{22} \nabla \varphi\right)$ are equal and opposite. Equating them reveals the result of Smoluchowski (1903):

$$
C c=\frac{\Delta \varphi}{\Delta p}=-\frac{L_{12}}{L_{22}}=\frac{\varepsilon \zeta}{\eta F_{o} \sigma_{b}}
$$

where $C c$ is known as the electrokinetic coupling coefficient. Alternatively, Equation (6) can be written as (Jouniaux and Pozzi, 1995):

$$
C c=\frac{\Delta \varphi}{\Delta p}=\frac{\varepsilon \zeta}{\eta \sigma_{f}} \frac{F}{F_{o}}
$$

where $\sigma_{f}$ is the fluid conductivity, $F$ is the formation factor for the current sample conditions, $F=\sigma_{f} \sigma_{b}{ }^{-1}$, and $F_{o}$ is the formation factor when surface conduction is absent, measured using a highly conducting pore fluid. The ratio $F \cdot F_{o}{ }^{-1}$ is a correction factor to include the effect of surface conductivity and allows calculation of the zeta potential when surface conduction cannot be neglected. Equations (6) and (7) rely on the assumption that fluid flow is laminar; an assumption that can be violated during hydraulic fracturing of intact rocks (Fitterman, 1978; Morgan, 1989).

\section{Experiments}

Hydraulic fracture testing described here used two different specimen configurations: (1) unconfined Sierra granite cores, and (2) triaxially confined Sierra granite cubes. Experiments using the unconfined cores were designed to investigate the SP response during hydraulic fracturing in a simplified testing configuration. Additional experiments with these cores measured the SP response during hydraulic fracturing with non-conducting liquid $\mathrm{CO}_{2}$, and quantified the electrical resistivity variation during hydraulic fracturing. The Sierra granite cubes were used to test the spatial SP response during hydraulic fracturing, simulating a field survey, so these were confined in a more realistic stress state. Additional experiments were performed using a point load testing device to study the SP response during tensile fracturing, while minimizing electrokinetic contributions. Hydraulic fracturing and point load experiments and the test conditions for each are summarized in Table 1. Finally, the hydroelectric transport parameters for Sierra granite were determined, and these tests are described in Section 4. 


\subsection{Unconfined Sierra Granite Cores}

To investigate the fundamentals of the SP response during hydraulic fracturing, a simple testing configuration (Figure 1) was devised using $57 \mathrm{~mm}$ diameter, $102 \mathrm{~mm}$ long Sierra granite core specimens taken from the same block. A $6.35 \mathrm{~mm}$ diameter axial hole was drilled to within $25 \mathrm{~mm}$ of the bottom of each specimen. This hole was then overcored at $9.53 \mathrm{~mm}$ diameter for the top $25 \mathrm{~mm}$ of the sample to create a total vertical exposed bore length of $50 \mathrm{~mm}$ in the sample center. The injector was prepared by machining a groove in $6.35 \mathrm{~mm}$ OD stainless steel tubing for a silicon rubber o-ring which sat upon the lip created by the over-coring. The space around the steel tubing above the o-ring was filled with high-strength, non-conductive epoxy. The samples were placed in an oven at $150^{\circ} \mathrm{C}$ for 24 hours to cure the epoxy and eliminate excess pore fluid.

Self-potentials were monitored on 6 electrodes spaced $25 \mathrm{~mm}$ around the specimen perimeter as shown in Figure 1. The electrodes were $\mathrm{Ag} / \mathrm{AgCl}$ resting $\mathrm{EKG}$ electrodes (3M Red Dot) and were cut to $22 \times 12 \mathrm{~mm}$ rectangles. The reference electrode was a $25 \mathrm{~mm}$ bare wire end located in the center of the cores and ported out through the injection tubing. Voltage measurements were recorded at $5 \mathrm{kHz}$, while the injection pressure was logged on an independent acquisition system at $10 \mathrm{~Hz}$.

The specimens were wetted with water by placing them first under vacuum to eliminate excess air, then under $2 \mathrm{~m}$ head for at least 48 hours while soaking in a water bath of $0.001 \mathrm{M} \mathrm{NaCl}$ solution $\left(\sigma_{f}=0.013 \mathrm{~S} / \mathrm{m}\right.$, or $\left.\rho_{f}=77 \Omega-\mathrm{m}, \mathrm{pH}=6.0\right)$. After wetting the samples, the resistivity of the $\mathrm{NaCl}$ solution decreased to a steady value of about 67 $\Omega-\mathrm{m}$ due to contribution of salts from the rock. This resulting solution was used as injectate and was applied to the specimens at a constant rate of $0.15 \mathrm{ml} / \mathrm{s}$ by a syringe pump.

\subsection{Triaxially Confined Sierra Granite Cubes}

Large Sierra granite cubes were used to test the spatial SP response during hydraulic fracturing. These samples were $260 \mathrm{~mm}$ on a side, and the injector mechanism was similar to that in the Sierra granite cores, with an exposed length of $76 \mathrm{~mm}$ in the sample center. The cubes were placed in a large true-triaxial load cell and pressurized 
with flat jacks to a stress state of $\sigma_{\mathrm{H}}=5.0 \mathrm{MPa}, \sigma_{\mathrm{h}}=1.25 \mathrm{MPa}$, and $\sigma_{\mathrm{v}}=1.75 \mathrm{MPa}$. The test specimens were surrounded by non-conductive PEEK plastic plates which have a grid of machined grooves to allow for movement of fluid around the sample.

Self-potential signals were recorded on the top surface of the sample on a radial array of 6 electrodes equally spaced $50 \mathrm{~mm}$ from the injection point. The reference electrode was located $145 \mathrm{~mm}$ from the injection point in one corner of the top surface. The SP electrodes were $13 \mathrm{~mm}$ square copper shims with a soldered jumper wire. These were glued to the PEEK top plate and pressed against the specimen by the confining load. Self-potential measurements were sampled at $500 \mathrm{~Hz}$ for 128 second sweeps.

The specimens were wetted with $0.001 \mathrm{M} \mathrm{NaCl}$ solution under $1 \mathrm{~m}$ head for 48 hours in a water bath. Water was applied to the sample center at a constant rate of $0.15 \mathrm{ml} / \mathrm{s}$ by a syringe pump, and injection pressure was recorded on an independent acquisition system at 4 samples per second.

A wide-band acoustic emission (AE) sensor (Manthei et al., 2000) was placed on the center of the top surface of the cubes adjacent to the injection point. We configured the AE sensor to output a step-pulse when triggered so we could detect the timing of micro-seismic events. The sensor did not provide any information about the magnitude or waveform of the $\mathrm{AE}$ events.

For all testing (both cores and cubes), care was taken to remove air from the injection system (Morgan, 1989). The effect of the steel injection tubing on the resistivity structure of the samples was negligible since the tubing was surrounded by a non-conducting epoxy and not in direct contact with the specimen. Efforts were made to ensure that our samples were electrically isolated. The electrodes were allowed to equilibrate with the system prior to testing, and electrode polarization effects were not encountered.

\subsection{Point Load Fracturing}

To investigate the SP response during fracturing while minimizing electrokinetic contributions, we utilized a point load testing device (ISRM, 1985) to create a tensile fracture in core specimens of Sierra granite, Westerly granite, and micritic limestone. These cores were $50 \mathrm{~mm}$ in diameter and $50 \mathrm{~mm}$ long, and were wetted in $0.001 \mathrm{M} \mathrm{NaCl}$ 
solution for at least 24 hours to support electrical conduction. Two $\mathrm{Ag} / \mathrm{AgCl}$ electrodes were positioned on the sample perimeter, and with the reference electrode located on one end of the sample, one dipole was on the same side of the fracture while the other dipole spanned the fracture. SP measurements were recorded at $50 \mathrm{kHz}$. The cones of the point load device were made from hardened steel, but were electrically isolated from each other because the loading mechanism was a hydraulic ram and insulated by oil and o-rings. Electrical tape was wrapped around the cores so the fractured halves would not fly apart, and the specimens were instrumented with an AE sensor to record the seismic waveform.

\subsection{Note About Data Acquisition}

Self-potentials were recorded on a 14-Bit digitizer with an input impedance of $2 \mathrm{M} \Omega$. Normally an input impedance of $10 \mathrm{M} \Omega$ or higher is desirable, but in order to record multiple channels at a high sampling rate we were limited to this slightly lower value. To minimize instrument loading, care was exercised to ensure good contact between the electrodes and the test specimen. In general, our electrodes had a contact resistance ranging from $100-200 \mathrm{k} \Omega$. Using the analogy of resistors in parallel, this contact resistance implies that at least $90 \%$ of the source current was flowing through the specimen, while less than $10 \%$ was lost through the instrument. The implication of current loss is that the magnitude of the measured SP is reduced, but the qualitative interpretation is unchanged. In cases where accurate voltage measurement was critical, a single channel unity-gain preamp with input impedance of $100 \mathrm{M} \Omega$ was used to minimize instrument loading.

\section{Material Properties - Sierra Granite}

Sierra granite is a medium-grained, white to light-gray, biotite-hornblende granodiorite found in the Sierra Nevada of California. Our specimens are from the Raymond, California quarry owned by the Cold Spring Granite Company. The hydroelectric transport properties for Sierra granite are summarized in Table 2, and the methodology to determine them described below. 


\subsection{Porosity and Permeability}

The porosity $(\phi)$ of Sierra granite was measured by vacuum-saturating five core specimens, measuring their wet weight, then oven-drying and measuring their dry weight. Porosity was calculated as the ratio of the volume of the pores to the total specimen volume and found to be $0.9 \%$, consistent with results for Sierra granite in Berryman (2005).

Permeability was measured as a function of radial pressure drop using the method outlined by Bernaix (1969). Sierra granite specimens were prepared as shown in Figure 1, except that the overall length was $127 \mathrm{~mm}$ and the exposed length in the center was 76 $\mathrm{mm}$. The injection pressure in the center of the sample was kept constant for increasing increments, while the pressure on the outside of the sample was atmospheric. The flow rate for each pressure increment was measured and the permeability $(k)$ computed by (Bernaix, 1969):

$$
k=\frac{Q \eta}{2 \pi l P \rho g} \log \frac{r_{2}}{r_{1}}
$$

where $Q$ is the flow rate, $l$ is the exposed length in the center of the core $(76 \mathrm{~mm}), P$ is the head drop across the radius of the sample, $\rho$ is the fluid density, $r_{2}$ is the outer radius of the core $(28.6 \mathrm{~mm})$, and $r_{l}$ is the radius of the exposed section $(3.2 \mathrm{~mm})$.

Figure 2 shows the results of the radial permeability testing, demonstrating that at large pressure gradients the permeability increases due to dilatancy of micro-cracks (Bernaix, 1969; Zoback and Byerlee, 1975). The permeability at zero pressure drop $\left(k_{o}\right)$ was extrapolated from the experimental data to be $1.0 \times 10^{-18} \mathrm{~m}^{2}$, which is similar to values reported for granite specimens by Tosha et al. (2003), Zoback and Byerlee (1975), and Brace et al. (1968). At the maximum tested pressure drop of $5 \mathrm{MPa}$, the permeability increased by about $275 \%$ of $k_{o}$. Our data show that the specimen permeability varies with pressure drop as:

$$
k=1.0 \times 10^{-18} e^{2.5 \times 10^{-4} P}
$$

where $k$ is in $\mathrm{m}^{2}$ and $P$ is in $\mathrm{kPa}$. The exponential increase is similar in form to the variation observed by Bernaix (1969). 


\subsection{Conductivity and Formation Factor}

Specimen conductivity measurements were made using a four electrode configuration on $28 \mathrm{~mm}$ diameter, $100 \mathrm{~mm}$ long core specimens. Copper electrodes on the ends of each specimen applied alternating current at $100 \mathrm{~Hz}$. A small sponge soaked in salt water lowered the contact resistance of these electrodes aiding current flow into the sample. Copper ring electrodes monitored the received voltage, and a preamp with $100 \mathrm{M} \Omega$ input impedance was used to minimize instrument loading.

The conductivity of Sierra granite when saturated with $0.001 \mathrm{M} \mathrm{NaCl}\left(\sigma_{f}=\right.$ $0.015 \mathrm{~S} / \mathrm{m})$ was found to be $\sigma_{b}=1.25 \times 10^{-4} \mathrm{~S} / \mathrm{m}(8000 \Omega-\mathrm{m})$ which is in good agreement with results reported by Brace et al. (1965) for various types of granite with similar pore fluids.

The formation factor $(F)$ is calculated as the ratio of the pore fluid conductivity to the bulk specimen conductivity. When saturated with $0.001 \mathrm{M} \mathrm{NaCl}$ solution, the specimen conductivity is dominated by surface conduction, and $F=120$. To determine the true formation factor $\left(F_{o}\right)$, the samples were saturated with conductive $0.22 \mathrm{M} \mathrm{NaCl}$ solution $\left(\sigma_{f}=1.85 \mathrm{~S} / \mathrm{m}\right)$ so that the effect of surface conductivity was negligible. The resulting value $F_{o}=1000$ is comparable to that reported by Tosha et al. (2003) for Inada granite with similar porosity.

In the capillary model, the formation factor $F_{o}$ can be written as (Ishido and Mizutani, 1981; Lorne et al., 1999b):

$$
F_{o}=\frac{\tau_{e}^{2}}{\phi}
$$

where $\phi$ is the porosity, and the electrical tortuosity is calculated to be $\tau_{e}=3$. The bulk sample conductivity can be written as (Lorne et al., 1999b):

$$
\sigma_{b} \cong \frac{\sigma_{f}}{F_{o}}+\sigma_{s}
$$

and the surface conductivity calculated to be $\sigma_{s}=1.1 \times 10^{-4} \mathrm{~S} / \mathrm{m}$, a value within the reported range for quartz-rich rocks (Brace et al., 1965; Lorne et al., 1999b). Again, from the capillary model (Yohida, 2001):

$$
\frac{1}{F}=\frac{\sigma_{b}}{\sigma_{f}}=\frac{1}{F_{o}}+\frac{2 \Sigma_{s}}{m \sigma_{f} F_{o}}
$$


where $m$ is the average hydraulic radius, and $\Sigma_{s}$ is the specific surface conductance, $\Sigma_{s}=8$ x $10^{-9} \mathrm{~S}$ (Watillon and de Backer, 1970; Revil et al., 1999). Combining Equations (11) and (12):

$$
\sigma_{s}=\frac{2 \Sigma_{s}}{m F_{o}}
$$

and the mean hydraulic radius is found to be $m=1.5 \times 10^{-7} \mathrm{~m}$, in good agreement with results of Brace et al. (1968) and Tosha et al. (2003) for intact granite samples.

\subsection{Electrokinetic Coupling Coefficient}

The electrokinetic coupling coefficient $(\mathrm{Cc})$ was determined for two $28 \mathrm{~mm}$ diameter, $57 \mathrm{~mm}$ long intact cores of Sierra granite. The samples were coated with silicone adhesive before being inserted into a length of plastic tubing of the same internal diameter, and saturated under vacuum with $0.001 \mathrm{M} \mathrm{NaCl}(\mathrm{pH}=6.0)$ solution for more than 48 hours. At the time of testing, the pore fluid conductivity increased from initially $0.013 \mathrm{~S} / \mathrm{m}$ to $0.020 \mathrm{~S} / \mathrm{m}(50 \Omega-\mathrm{m})$ due to dissolution of salts from the rock matrix.

On each end of the sample tube, plastic flanges contained $25 \mathrm{~mm}$ circular copper mesh electrodes. The voltage across the specimens was recorded at $200 \mathrm{~Hz}$, and a unitygain preamp with $100 \mathrm{M} \Omega$ input impedance ensured accurate voltage measurement. A pressure transducer monitored the fluid pressure at the inlet of the testing device, while the outlet pressure remained constant at atmospheric. Transient fluid pressure changes were generated using an injection pump and conveyed to the samples with nylon tubing.

In the temporal response, the SP closely mimicked the fluid pressure changes, and the $\mathrm{Cc}$ was determined as the linear slope of the $\mathrm{SP}$ versus pressure drop curve. The $\mathrm{Cc}$ for Sierra granite with $0.001 \mathrm{M} \mathrm{NaCl}$ pore fluid was found to be $-175 \mathrm{mV} / \mathrm{MPa}$. This value is about one order of magnitude greater than that reported by Reppert and Morgan (2003) for intact Westerly granite, and about one order of magnitude less than that reported by Morgan et al. (1989) for crushed pieces of Westerly granite, both using similar pore fluids. The $\mathrm{Cc}$ determined for Sierra granite is also about 3 times larger than that reported by Tosha et al. (2003) for Inada granite with a similar pore fluid.

The zeta potential was calculated to be $-35 \mathrm{mV}$ using Equation (7) and the material properties listed in Table 2. Similar values were reported by Reppert and 
Morgan (2003) for intact Westerly granite $(-20 \mathrm{mV})$, by Tosha et al. (2003) for intact Inada granite $(-50 \mathrm{mV})$, by Lorne et al. (1999a) for crushed granodiorite $(-52 \mathrm{mV})$, and by Morgan et al. (1989) for crushed Westerly granite $(-40 \mathrm{mV})$ and fractured Westerly granite $(-38 \mathrm{mV})$.

\section{Results}

\subsection{Self-Potential Observations During Hydraulic Fracturing of Unconfined Sierra} Granite Cores

Tensile fractures were induced in Sierra granite cores by applying water to the sample center at a constant rate. There was no confining load on these specimens, yet fracture geometry was consistent: axial along the entire exposed length $(50 \mathrm{~mm})$ at the center. Breakdown pressure averaged about $10 \mathrm{MPa}$, but was variable despite all samples originating from the same block. The specimen halves did not separate following fracturing, and generally about $1 \mathrm{MPa}$ injection pressure was required to force water through the fracture at the flow rate of $0.15 \mathrm{ml} / \mathrm{s}$. Using the Cubic Law, we estimate the average fracture width to be approximately $10 \mu \mathrm{m}$ and the fracture permeability to be approximately $10^{-11} \mathrm{~m}^{2}$.

For low injection pressures the variation of $\mathrm{SP}$ and pressure drop is linear, indicating a constant $\mathrm{Cc}$ (Figure 3), where the $\mathrm{Cc}$ is calculated as the local slope of the SP versus injection pressure curve. However, for injection pressures $>2 \mathrm{MPa}$ (fluid pressure gradient $>80 \mathrm{MPa} / \mathrm{m}$ ), the magnitude of the Cc increases exponentially with increasing pressure drop (Figure 4). Figure 5 shows the cumulative data from 7 samples of Sierra granite, demonstrating that the magnitude of the $\mathrm{Cc}$ prior to hydraulic fracturing increases by $80 \%$ as described by the best fit equation:

$$
|C c|=200+3.7 e^{3.75 \times 10^{-4} P}
$$

where $P$ is in $\mathrm{kPa}$ and $C c$ is in $\mathrm{mV} / \mathrm{MPa}$.

The $\mathrm{Cc}$ measured here is the change in observed voltage for a change in the injection pressure. Since the pressure on the outside of the sample is atmospheric, the injection pressure is equal to the pressure drop across the radius of the core cylinder. The specimen configuration creates radial flow of both fluid and current, so the $\mathrm{Cc}$ is

measured in an unconventional way. To ensure the validity of determining the $\mathrm{Cc}$ using 
this radial flow method, we measured the $\mathrm{Cc}$ for Sierra granite in the traditional configuration where flow is axial through a cylindrical specimen (Section 4.3). The Cc was thus determined to be $-175 \mathrm{mV} / \mathrm{MPa}$, nearly identical to the average value of -200 $\mathrm{mV} / \mathrm{MPa}$ measured using the radial method.

The Cc reported is a scalar quantity and only valid only for radial fluid and current flow. Stress-induced changes in the flow networks caused by micro-crack dilatancy leads to anisotropic material properties. The complete $\mathrm{Cc}$ tensor is not measured in this work, and flow in other directions through the sample may create a different SP response. Additionally, we assume that axial flow through the top and bottom of the core specimens contributes negligibly to the overall flows of fluid and current. This assumption has been addressed by Bernaix (1969) for radial divergent fluid flow.

The data in Figure 5 show considerable scatter for injection pressures $<\sim 2 \mathrm{MPa}$, which results from limitations of the pressure measurement system. At early times in each hydraulic fracture test, the fluid pressure was low and changed slowly, and signal noise contributed significant variability to the Cc calculation which was made every $0.1 \mathrm{~s}$. As the fluid pressure increased above $\sim 2 \mathrm{MPa}$, however, the signal to noise ratio was greater, and the percent variation of the Cc shows excellent consistency among the various test specimens.

The magnitude of the SP response at each of the circumferential electrodes is related to varying quantities of fluid infiltration prior to hydraulic fracturing. Since SP is proportional to the quantity of infiltrating fluid (Yoshida, 2001), areas with more fluid infiltration show a greater SP response. In most testing on unconfined core specimens, this variation indicated the impending fracture geometry by revealing the preferred direction of injectate infiltration (Figure 6). The magnitude of the SP varied between electrodes by only a few percent.

At the time of failure, an anomalous SP spike is created as injectate rushes into the cracked zone, and is observed on electrodes close to the fracture. The magnitude of the SP spike is on the order of $100 \mathrm{mV}$, and it peaks 20 - $40 \mathrm{~ms}$ after apparent hydraulic fracture initiation (Figure 6). The time of fracturing is inferred from the SP trend of 
electrodes far from the crack as the time when the SP begins to decrease, mimicking the injection pressure.

After fracturing, the SP continues to mimic the injection pressure as the pressure declines and stabilizes (Figure 4a).

\subsection{Electrical Resistivity Variation During Hydraulic Fracturing}

We measured the electrical resistivity of Sierra granite core specimens during hydraulic fracturing and found it to decrease slightly immediately prior to fracture initiation, similar to observations for compression and shear loading by Brace and Orange (1968), Wang et al. (1978), Lockner and Byerlee (1986), and Chen and Lin (2004). We prepared 3 samples of Sierra granite, as shown in Figure 1, and used a laboratory vice to control the fracture direction. We arranged the electrodes so that the current dipole and the voltage monitoring dipole were on opposite sides of the induced fracture, and used a preamp with $100 \mathrm{M} \Omega$ input impedance on the voltage monitoring dipole to minimize instrument loading. Injection parameters were the same as in previous testing.

As injection pressure increased, the bulk specimen resistivity decreased by up to $2 \%$ due to injectate infiltration into dilatant micro-porosity (Figure 7). After fracturing, the resistivity decreased by about $35 \%$ as the water-filled fracture added a conductive current path. The new steady-state resistivity value was attained about $200 \mathrm{~s}$ after fracturing.

The resistivity decrease observed prior to failure is created by the same mechanism that generates the electrokinetic SP observed in our testing. Whereas the resistivity variation is only a few percent (near the practical limits of detection), the SP response is quite large and well within detectable limits.

\subsection{Hydraulic Fracturing with Liquid $\mathrm{CO}_{2}$}

To investigate the SP response during hydraulic fracturing while minimizing electrokinetic effects, we fractured one core sample of Westerly granite (Figure 1) with liquid $\mathrm{CO}_{2}$. The core was wetted by soaking in $0.001 \mathrm{M} \mathrm{NaCl}$ solution for $>48 \mathrm{hrs}$, after which excess water and air were eliminated under vacuum. Water in sample lattice was 
minimal, and liquid $\mathrm{CO}_{2}$ is non-conducting, yet minor electrokinetic effects were expected (Moore et al., 2004).

The SP and injection pressure can be seen in Figure 8. The sample failed in an episodic manner where smaller failures were noted at 90,94 , and $98 \mathrm{~s}$, and $\mathrm{CO}_{2}$ gas could be heard escaping through localized fractures. The main failure event was explosive because of the volume expansion accompanying the phase transition of liquid $\mathrm{CO}_{2}$ to gas. The pressure record indicates the timing of the explosion by a resurgent pressure after dropping below $5 \mathrm{MPa}$ (pressure of $5.7 \mathrm{MPa}$ is required to maintain $\mathrm{CO}_{2}$ in a liquid phase at $20^{\circ} \mathrm{C}$ ). There is a considerable SP response associated with failure, sometimes exceeding the $\pm 1 \mathrm{~V}$ set limit of the digitizer. In the expanded time scale of Figure 8a, there are 3 episodes of brief negative SP spikes (lasting $\sim 30 \mathrm{~ms}$ ) immediately following rupture, and one broad positive anomaly (lasting $\sim 500 \mathrm{~ms}$ ) at the time of phase transition and explosion.

\subsection{The Spatial SP Response During Hydraulic Fracturing - a simulated surface survey}

Resolving the direction of hydraulic fracture propagation is of great interest to both earth scientists and engineers for many applications. We successfully measured the spatial SP response during hydraulic fracturing of a $260 \mathrm{~mm}$ cube of Sierra granite. The cube was placed in a true-triaxial stress state $\left(\sigma_{\mathrm{H}}=5.0 \mathrm{MPa}, \sigma_{\mathrm{h}}=1.25 \mathrm{MPa}\right.$, and $\sigma_{\mathrm{v}}=$ 1.75 MPa) and the SP measured on a radial array of 6 electrodes (T1-T6) about the injection point on the top surface of the sample. An acoustic emission sensor glued to the sample sent a time stamp to the digitizer for each $\mathrm{AE}$ event over its threshold level. The raw SP data, injection pressure, and $\mathrm{AE}$ record during hydraulic fracturing are shown in Figure 9.

The hydraulic fracture was observed after testing to be single-lobed and vertically oriented, propagating in the direction orthogonal to the minimum compressive principal stress $\left(\sigma_{\mathrm{h}}\right)$, or towards electrode $\mathrm{T} 1$. The injection pressure and $\mathrm{AE}$ records show that the initial fracture occurred at a fluid pressure of $12 \mathrm{MPa}$ and did not initially break through to the sample edge. Fracturing continued for $\sim 18 \mathrm{~s}$ until reaching the perimeter, at which time the frequency of AE events declined, and the injection pressure stabilized at about 
3.8 $\mathrm{MPa}$ (Figure 9). During fracture growth the fluid pressure continually declined as the increasing length of the fracture imposed a greater leverage on the crack tip (Economides and Nolte, 1989).

At first glance the SP record closely mimics the injection pressure. No variation is immediately evident amongst the six electrodes at the scale shown in Figure 9. However, expanding the SP response for times close to the failure event reveals systematic spatial variation of the SP measured at the various electrodes. To clarify the spatial variation we subtracted the time series of electrode T5 (whose value was nearest the average of the six electrodes) from each of the other measuring electrodes creating a residual SP trace for each (Figure 10). Viewed on a spatial grid (Figure 11), the fracture geometry is indicated by an asymmetric SP response, with the direction of fracture propagation shown by a positive residual SP anomaly, and the direction opposite fracturing by a negative anomaly.

The testing described above was the second attempt with a large block of Sierra granite. The first test was compromised when the epoxy around the injection tubing failed, allowing water to escape before the rock fractured. It is interesting, however, to note the SP response during this failure event, which was spatially quite different from a hydraulic fracture, but was nevertheless a tensile fracture event. The SP response generally followed the fluid pressure, which had a similar form to a hydraulic fracture. However, the SP response lacked any systematic spatial variation, which is expected because the failure in this case was a point source in the center of the electrode array.

The combined results of these tests suggest that a systematic spatial SP variation may be measured by a surface electrode array indicating fracture geometry at depth.

\subsection{Point Load Testing - Fracture Induced Self-potentials}

To investigate the SP response during fracture initiation while minimizing electrokinetic contributions, we fractured wet core specimens of Sierra and Westerly granite in a point load device as described in Section 3.3. An additional limestone specimen was tested to observe the SP response during fracture of a rock specimen not containing piezoelectric minerals. 
We observed a $150-400 \mathrm{mV}$ transient SP spike commencing near the time of failure and decaying within approximately $500 \mu \mathrm{s}$, with no SP response prior to fracturing. The magnitude and duration of the SP transient was consistent among the various rock types tested, including limestone, which suggests that this SP response is not created by a piezoelectric source. A representative SP response during point load fracturing is shown in Figure 12. Interestingly, the acoustic emission data indicated that the maximum SP response was not attained until some 100's of $\mu$ s following fracturing. The magnitude of the transient SP observed during point load testing is similar to that of SP transients observed at the time of hydraulic fracture initiation, however the time constant of the SP spike in point load testing is about an order of magnitude less.

\section{Discussion}

\subsection{The Origin of SP Signals Associated with Hydraulic Fracturing}

\subsubsection{Electrokinetics}

Excellent correlation of injection pressure and SP indicates that the SP response during hydraulic fracturing is created primarily by electrokinetic coupling. In most testing we observed linear variation of the SP with injection pressure, as predicted by electrokinetic theory (Equation 6), where the constant of proportionality is the coupling coefficient. It was possible to overlay the pressure drop and SP curves to easily observe this correlation (Figures $3 \mathrm{a}$ and $4 \mathrm{a}$ ). At injection pressures approaching the breakdown pressure, however, the $\mathrm{Cc}$ became non-linear, and the magnitude of the $\mathrm{Cc}$ increased up to $80 \%$ in an exponential trend (Figure 5).

An increasing $\mathrm{Cc}$ has been observed to be associated with increasing permeability during the onset of dilatancy in uniaxial loading prior to failure (Jouniaux and Pozzi, 1995; Lorne et al., 1999b). In these reported cases, the Cc increases by anywhere from $30 \%$ to $100 \%$, similar to the increase observed in this testing.

The increasing $\mathrm{Cc}$ observed here is most likely related to increasing permeability caused by dilatancy of micro-cracks at high pore pressures (Zoback and Byerlee, 1975). Bernaix (1969) discussed the theory of radial divergent permeability testing and concluded that for some pressure-sensitive materials permeability can increase by orders of magnitude at high fluid pressure gradients. We found that the permeability of our 
Sierra granite specimens increased in an exponential trend by as much as $275 \%$ at injection pressures approaching the breakdown pressure (Figure 2). Combining Equations (9) and (14), our experimental data show that for injection prior to hydraulic fracturing, the magnitude of the $\mathrm{Cc}$ increases with permeability as:

$$
|C c|=200+3.7 \times 10^{27} k^{1.5}
$$

where $C c$ is in $\mathrm{mV} / \mathrm{MPa}$ and $k$ has units of $\mathrm{m}^{2}$ (Figure 13). Lorne et al. (1999b) similarly parameterize $\mathrm{Cc} \propto k^{t}$, where $t$ ranges from about 0.5 to 1 for samples undergoing compaction.

Jouniaux and Pozzi (1995) argue that changes in the Cc during deformation are created by variations in the effect of surface conductivity. Specifically, at greater permeability the surface conductivity is reduced, since it is inversely related to the pore size, and the electrical gradient increases to equilibrate the convection current. Increasing the electrical gradient for the same pressure gradient results in a larger Cc. For injection preceding hydraulic fracturing of Sierra granite, the specimen resistivity (and formation factor, $F$ ) was observed to decrease by only about $2 \%$ (Figure 7 ). This change may result in a slight decrease of the $\mathrm{Cc}$, but it is incompatible to produce the observed $80 \%$ increase.

Lorne et al. (1999b) concur that the effect of surface conductivity is insufficient to produce the changes in the $\mathrm{Cc}$ observed in their testing. Similar to our findings, their compaction data show significant variation of the Cc with permeability, but only slight variation of the formation factor. They propose that competing changes in the electrical and hydraulic percolation networks result in an increased Cc during dilatancy. In their model, the $\mathrm{Cc}$ is proportional to a geometrical factor $(G)$ which is the ratio of the electrical tortuosity to the hydraulic tortuosity.

At high injection pressure, dilatancy of micro-cracks in our Sierra granite specimens causes the hydraulic tortuosity to decrease. For Poiseuille flow, the hydraulic tortuosity is inversely proportional to the permeability, so our lab data suggest that the tortuosity decrease is substantial. Similarly, the electrical tortuosity is inversely proportional to the electrical conductivity (and formation factor), so our lab data indicate that the electrical tortuosity decreases only slightly. The net result is an increased geometric factor and an increased Cc. 
Other variables which may affect the Cc include: a) increasing porosity at high pore pressure, b) increasing zeta potential, c) increased effective viscosity by electroviscous effects, and d) flow separation at high fluid velocity. The porosity increase at pore pressures approaching failure was calculated to be only a few percent using poroelastic constants for Sierra granite reported by Berryman (2005); insufficient to produce any major change in the Cc. Fresh surfaces generated as micro cracks develop may have a different zeta potential than previously exposed surfaces (Sharma, et al., 1987, Jouniaux and Pozzi, 1995). The electrokinetic contribution from the new surface area may be quite different from the surrounding porosity, but unfortunately this effect is difficult to quantify. Finally, the effective viscosity of the fluid may increase as a large electric field (up to $100 \mathrm{~V} / \mathrm{m}$ ) is created from the SP gradient (Ren et al., 2001, Revil and Pessel, 2002). To test the influence of this effect, we wrapped one specimen in aluminum foil which was connected by a jumper wire to the reference electrode, thereby shorting the electric field. We observed no change in the breakdown pressure or temporal injection pressure response, suggesting that electroviscous effects do not play a significant role in the evolution of the $\mathrm{Cc}$ during hydraulic fracturing. Finally, previous researchers have reported that for high fluid velocities flow separation and flow fingering can occur causing the Cc to decrease (Morgan, 1989; Middleton, 1997). Due to the low permeability of the Sierra granite specimens, fluid flow prior to fracturing remains laminar even at high injection pressure where the maximum Reynolds number $\left(R_{e}\right)$ is on the order of $10^{-7}$.

Near the time of fracture initiation, we observed an anomalous SP spike that deviated from the trend of the injection pressure (Figure 6), and which may be caused by enhanced electrokinetics as injectate rushes into the fracture. Figure $6 \mathrm{~b}$ shows that the SP transient peaks $20 \mathrm{~ms}$ after apparent fracture initiation. The time of fracturing is inferred from the other SP records as the time when the SP begins to decrease, mimicking the injection pressure decrease as the crack opens. Using the Cubic Law with an average fracture width of $10 \mu \mathrm{m}$, the flow velocity is about $2.5 \mathrm{~m} / \mathrm{s}$, meaning that approximately $10 \mathrm{~ms}$ is required for injectate to reach the sample perimeter. This value is in general agreement with the observed time of $20 \mathrm{~ms}$ required for the SP transient to peak after 
apparent fracture initiation, and suggests that the SP spike is related to flow through the new fracture.

Our conceptual model for the process creating this transient is: a) the hydraulic fracture opens and breaks through to the specimen perimeter instantaneously, b) injectate rushes into the new fracture void space which has a larger Cc since the effect of surface conduction is decreased in this high permeability zone, and the new surfaces have a larger zeta potential, and finally c) fluid pressure decreases which is mimicked by the SP response. After the fluid pressure reaches a new steady value, the SP on the electrode(s) which sensed the spike remains augmented by the amplitude of the spike. In this model the spike is essentially created by an increased $\mathrm{Cc}$ in the new fracture zone, and represents the transient SP response to the changing Cc. Supporting this conceptualization, we found that the $\mathrm{Cc}$ for flow through an existing fracture (created by hydraulic fracturing) was up to $50 \%$ larger than the $\mathrm{Cc}$ for the intact rock.

\subsubsection{Contact Electrification}

Point load testing investigated contributions from tensile rock cracking to the overall SP response during hydraulic fracturing. Wet rock specimens were fractured and a transient SP spike was observed near the time of failure that may be caused by contact electrification (or separation electrification). In this phenomenon, oppositely charged crack wall surfaces are created as materials rip apart (Ogawa et al., 1985; Enomoto and Hashimoto, 1990; Horn and Smith, 1992; Kanagy and Mann, 1994). Electrons migrate to surfaces during contact or separation based on the work function of each surface. Differences in the work functions of opposing surfaces, arising from inhomogeneities, cause the surfaces to develop net opposite charge. The resulting electric field drives a current through the saturated rock porosity.

A representative SP response (across the fracture) during point load testing is shown in Figure 12, along with AE information. The AE waveform indicates the time of fracture initiation, since the sensor is very close to the fracture. The maximum SP response is not attained until $\sim 700 \mu$ s following initial cracking. After the tensile fracture event, the sample halves are displaced from one another by sliding parallel to the crack walls due to continued application of load from rebound of the testing device. An electric 
field across the charged crack walls is created by separation electrification, and the resulting SP is measured on the sample surface. The time lag between sample failure and the maximum SP response may result from the time required for the sample halves to come to rest following the fracture event.

To validate the model of charged crack walls generating an SP transient, we can conceptualize the fractured rock specimen as a simple RC circuit. Here, the separated charged crack surfaces act as a capacitor, and incidental contact of the wet specimen halves provides a resistive pathway for the current flow that generates the SP on the sample surface. If the fracture void space is filled with air, and the fracture surface area is $2.5 \times 10^{-3} \mathrm{~m}^{2}$ with an average separation of $10 \mu \mathrm{m}$, we calculate a capacitance of about $2 \mathrm{nF}$. Using the measured resistance between electrodes on opposite sides of the fracture $(\sim 200 \mathrm{k} \Omega$ ), we can calculate a time constant for the RC circuit of about $500 \mu \mathrm{s}$, consistent with the observed decay of SP transients in our point load testing.

While the magnitude of the SP transients found during point load testing is similar to that of the anomalous SP at failure during hydraulic fracturing, the time constant of the SP spikes in point load testing is about an order of magnitude less. In a futile effort to detect any SP transients of this shorter time scale during hydraulic fracturing, we recorded SP measurements at $20 \mathrm{kHz}$ for 2 samples. The absence of such transient spikes suggests that fracture-induced SP does not contribute to the overall SP response during hydraulic fracturing. Finally, any electric field created by contact electrification during hydraulic fracturing will be quickly shorted as the injectate moves into the fracture area.

\subsubsection{Piezoelectric Effects}

Sierra granite contains abundant quartz crystals that show a piezoelectric response. Yoshida et al. $(1997,1998)$ proposed a model whereby polarization of quartz grains is neutralized by compensating bound charges, and the neutral state is broken only when the stress state is changed rapidly. They used this model to explain electric potential changes observed during triaxial and direct shear loading. Similarly, Nitsan (1977) proposed that a rapid change in the piezoelectric field at the time of fracturing causes electromagnetic emissions observed during uniaxial loading. However, Ogawa et al. (1985) and Tuck et al. (1977) conclude that the net piezoelectric effect is cancelled 
because of the random orientation of grains, and Cress et al. (1987), Brady and Rowell (1986), Goldbaum et al. (2003), and Eccles et al. (2005) observed electrical emissions during compression and rupture of quartz-free basalt, chalk, and limestone.

We detected no SP response prior to sample failure during point load testing of granite samples where compression of quartz grains might have produced a net piezoelectric source current. Furthermore, we observed a SP response similar to that in Figure 12 when fracturing a limestone specimen that contained no piezoelectric minerals. We conclude that piezoelectric sources are not responsible for the SP observed during point load testing, and do not contribute to the SP observed during hydraulic fracturing.

\subsubsection{Co-Seismic Electrokinetics}

The process of material fracture generates a seismic disturbance which moves through the specimen and creates a co-seismic self-potential, a process often associated with seismoelectric conversion (Martner and Sparks, 1959; Pride and Morgan, 1991; Zhu et al., 1999). Fluid movement stimulated by the acoustic wave creates local charge displacements and SP through electrokinetic coupling. Therefore, we expect co-seismic electrokinetics to augment the SP response at (and after) the time of failure, since the samples in all testing were wet, and also that co-seismic SP will generally mimic the seismic waveform.

In Figure 12 both the $\mathrm{AE}$ and $\mathrm{SP}$ response are shown for a Westerly granite core failed by point load indentation. The prominent SP response does not mimic the $\mathrm{AE}$ signal and the $\mathrm{AE}$ signal is characterized by high frequency oscillations. There is possible correlation between the SP and AE response immediately following failure (0.437 s, Figure 12) where subdued SP oscillations of $\sim 30 \mathrm{mV}$ appear to mimic the $\mathrm{AE}$ waveform. While the SP response during hydraulic fracturing may be augmented by coseismic electrokinetics, we expect the effect is limited.

\subsubsection{Hydraulic Fracturing with Liquid $\mathrm{CO}_{2}$}

Hydraulic fracture testing with non-conducting liquid $\mathrm{CO}_{2}$ was designed to investigate the SP response during hydraulic fracturing when electrokinetic contributions were minimal. SP and injection pressure for this testing show that the specimen failed in 
an episodic manner (Figure 8), and $\mathrm{CO}_{2}$ gas could be heard escaping through localized fractures preceding the main rupture event. There was minimal SP response associated with these micro-fractures, however, showing only a slight decrease preceding bulk failure (Figure $8 b$ ). The lack of SP response for $\mathrm{CO}_{2}$ flow during these fracture events implies that electrokinetic coupling is primarily responsible for the SP response during hydraulic fracturing with water.

In the expanded time scale of Figure 8a, there are 3 episodes of brief negative SP spikes (lasting $~ 30 \mathrm{~ms}$ ) immediately following rupture, and one broad positive anomaly (lasting $\sim 500 \mathrm{~ms}$ ) at the time of phase transition and explosion. The brief negative SP spikes may result from contact electrification, since their large magnitude in the presence of non-conducting $\mathrm{CO}_{2}$ suggests they are not of electrokinetic origin. The broad positive SP spike associated with the $\mathrm{CO}_{2}$ phase transition and explosion, however, may be a result of rapid fluid disruption (RFD). Described by Johnston et al. (2001), RFD phenomena can create SP anomalies as vaporization of a liquid disturbs the phase interface and causes a charge separation. Our scenario is favorable to RFD since we have both high flow rates and rapid phase transition from liquid to gas. Furthermore, this SP response lasts noticeably longer than the previous spikes, so it probably wasn't created by contact electrification.

\subsection{Precursory Self-Potential Phenomena}

There has been much interest in interpreting electromagnetic anomalies thought to precede earthquake fault rupture. However, studies with the goal of forecasting seismic events have met with somewhat limited success (e.g. Corwin and Morrison, 1977; Morrison et al., 1979). Here, we propose that spatial information about an impending hydraulic fracture may be obtained from close examination of the SP record.

Yoshida et al. (1998), Yoshida (2001), and Eccles et al. (2005) demonstrated in the laboratory that SP signals are generated during shear and triaxial loading prior to rupture. They concluded that water flow into dilatant regions generates SP through electrokinetic coupling. Our hydraulic fracturing results similarly show an increasing SP trend preceding sample failure due to fluid infiltration into dilatant micro-crack porosity (Figures 4, 6, and 9). Furthermore, we obtained spatial SP information revealing the 
geometry of an asymmetric precursory response. Since the SP anomaly is proportional to the quantity of infiltrating fluid, areas with more fluid infiltration showed a greater SP. For hydraulic fracturing, fluid infiltration indicates increased permeability zones where fluid-induced stresses cause micro-cracks to separate, grow and coalesce to form a macro fracture (Bernaix, 1969; Shlyapobersky et al., 1994).

For the unconfined Sierra granite cores, the SP variation amongst the circumferential electrodes generally indicated the impending fracture geometry by an increasingly positive SP anomaly. For example, in Figure 6a, we observed that the SP response at electrode C6 was greatest, augmented by about 3\% above each of the other electrodes, indicating increased flow in that direction. After failure, we found that the hydraulic fracture was single-lobed and oriented toward C6. The precursory SP response predicted the impending hydraulic fracture orientation a few seconds before failure.

For some of the core specimens, however, the greatest SP response did not correlate to the orientation of the hydraulic fracture. Since all core specimens were unconfined, there was no asymmetric stress-state causing favorably oriented micro-cracks to open and create a preferred direction of injectate diffusion. Instead, the direction of infiltration was controlled by random flaws and heterogeneities. If these specimens had been confined, the precursory SP response would likely have indicated the impending fracture geometry with greater reliability.

In our testing on the large confined $260 \mathrm{~mm}$ Sierra granite cubes, we again found that an asymmetric spatial SP response developed prior to fracture initiation, responding to the preferred direction of injectate infiltration caused by the triaxial stress state. In Figure 10, the residual SP for all 6 electrodes on the top surface of the sample is shown. Electrodes T3 and T4 (opposite the direction of fracturing) show a decreasing trend, while electrodes $\mathrm{T} 1$ and T6 increase prior to failure. The subsequent fracture was orientated in the direction of electrodes T1 and T6 (Figure 11), as predicted by the increasing SP trend almost $5 \mathrm{~s}$ prior to failure.

\section{Application to Field Monitoring}

Previous research has suggested that a directional SP response may not be apparent at large distances from a hydraulic fracture source (Wurmstich, 1995; Grinat el 
al., 2004). In related testing, Pinettes et al. (2002) showed results of a field experiment in which they circulated water through a fractured zone in granite at a depth of $150 \mathrm{~m}$. They concluded that the observed surface SP could not be explained by the deep circulation, and that incidental shallow flows due to leakage from the injection well dominated the overall SP response. This conclusion cast doubt on the feasibility of using surface SP measurements for field characterization of deep subsurface flows.

However, in hot dry rock geothermal areas, SP observations during hydraulic stimulations have been shown to correlate with injection pressure, and surface anomalies on the order of $10 \mathrm{mV}$ are reported (Kawakami and Takasugi, 1994; Marquis et al., 2002). Our laboratory results with large granite cubes indicate that a surface SP survey may provide geometrical information about an impending or recent hydraulic fracture. Carefully controlled field experiments at an intermediate scale are necessary to evaluate the ability of the SP method to respond to field hydraulic fracture events.

As discussed previously, precursory SP signals may indicate spatial variations in fluid infiltration and thus be related to the orientation of the impending hydraulic fracture. For field analysis of fracture orientation, a surface electrode array may be deployed in a radial pattern about the injection point. As fluid injection progresses, SP monitored in real-time may reveal asymmetric fluid infiltration preceding fracture initiation, enabling forecasting of fracture geometry. The depth of the fracture source affects the surface response, so that shallow fractures should yield better spatial resolution, while deeper fracture geometry would be more difficult to resolve.

Vertical down hole monitoring is another field scenario where geometric forecasting may succeed. Here, the injection bore could be instrumented with a vertical array of electrodes spanning the exposed length, and the SP monitored as the injection progresses. This configuration could reveal the precise location(s) of fluid infiltration along the exposed length of the borehole and allow the location of fracture initiation to be predicted.

The exact time of fracture initiation is evident from the raw SP time series. This is useful in field scenarios when employing microseismic monitoring methods as part of a geophysical arsenal (e.g. Wills et al., 1992). To determine the time of fracture initiation 
using microseismic methods, the wave propagation velocity must be estimated and long travel times can lead to large cumulative error.

During fracture treatment it is typical to have a wide variety of fluids injected into the reservoir, including water and polymer based fracturing fluids of varying viscosity, and resin-coated sand proppant. Because the electrokinetic response strongly depends on the composition of the injectate, the field SP response would differ widely for various fracturing fluids. Moreover, deep formations are typically brine-saturated, which not only lowers the value of the $\mathrm{Cc}$ (and thus the electrokinetic response), but also causes more rapid attenuation of the electric signal.

Finally, there are other recognized coupled flow phenomena (in addition to electrokinetics) that create self-potentials. For field injections, electrochemical selfpotentials (diffusion potentials) caused by ion concentration differences between the injectate and the pore fluid, and thermoelectric self-potentials created by differential thermal diffusion of ions in the pore fluid may influence the overall surface SP response (Nourbehecht, 1963; Corwin and Hoover, 1979; Hearst et al., 2000).

\section{Conclusions}

There are eight significant findings of this research:

1. The SP response during hydraulic fracturing is created primarily by electrokinetic coupling. Our results demonstrate excellent correlation of pressure drop and SP, indicating an electrokinetic source mechanism and adherence to basic electrokinetic theory.

2. For pressure drops less than $\sim 2 \mathrm{MPa}$, the $\mathrm{Cc}$ is constant, but at higher pressures the magnitude of the $\mathrm{Cc}$ increases in an exponential trend. The increasing $\mathrm{Cc}$ is related to increased permeability at high pore pressure due to dilatancy of micro-cracks, and the related decreased hydraulic tortuosity.

3. At the time of fracture initiation, an anomalous SP spike is observed on electrodes very close to the fracture which may be created by enhanced electrokinetics. The electrokinetic response of the fracture zone is augmented by an increased Cc, since the greater permeability of this zone reduces the effect of surface conductivity, while the zeta potential of the new surface area may be larger. 
4. A decrease in the bulk specimen resistivity prior to the onset of hydraulic fracturing confirms that injectate diffuses into dilatant micro-porosity under increasing pore pressure. After fracturing the specimen resistivity decreases by approximately $35 \%$.

5. Spatial SP measurements show a directional variation indicating the fracture geometry. In a simulated surface survey using a radial electrode array, the direction of fracture propagation was revealed by an increasingly positive SP response in the direction of flow.

6. Separation electrification and co-seismic electrokinetics create anomalous SP during rock fracture. However, these mechanisms probably do not contribute significantly to the overall SP observed during hydraulic fracturing.

7. Anomalous spatial SP variations prior to hydraulic fracturing are related to varying amounts of fluid infiltration and may forecast the geometry of the impending fracture. Precursory SP variations were observed up to $5 \mathrm{~s}$ prior to rupture, and the direction of fracture propagation could be predicted.

8. The hydroelectric transport properties of Sierra granite are described.

\section{Acknowledgements}

The authors would like to thank Frank Morrison, Steve Pride, and Ramsey Haught for helpful discussions, and reviewers Yves Guéguen and David Lockner for constructive comments. Financial assistance for this research has been provided in part by the Jane Lewis foundation. 


\section{References}

Bernaix, J. (1969), New laboratory methods of studying the mechanical properties of rocks, Int. Journ. Rock Mech. Min. Sci., 6, 43-90.

Berryman, J. G. (2005), Poroelastic fluid effects on shear for rocks with soft anisotropy, Geopys. J. Int., $161,881-890$.

Brace, W. F., A. S. Orange, and T. R. Madden (1965), The effect of pressure on the electrical resistivity of water-saturated crystalline rocks, J. Geophys. Res., 70(22), 5669-5678.

Brace, W. F., and A. S. Orange (1968), Electrical resistivity changes in saturated rocks during fracture and frictional sliding, J. Geophys. Res., 73, 1433.

Brace, W. F., J. B. Walsh, and W. T. Frangos (1968), Permeability of granite under high pressure, $J$. Geophys. Res., 73(6), 2225-2236.

Brady, B. T., and G. A. Rowell (1986), Laboratory investigation of the electrodynamics of rock fracture, Nature, 321, 488-492.

Corwin, R., and H. F. Morrison (1977), Self-potential variations preceding earthquakes in central California, Geophys. Res. Lett., 4, 171-174.

Corwin, R. F., and D. B. Hoover (1979), The self potential method in geothermal exploration; Geophysics, 44(2), 226-245.

Chen, G., and Y. Lin (2004), Stress-strain-electrical resistance effects and associated state equations for uniaxial rock compression, Int. Journ. Rock Mech. Min. Sci., 41, 223-236.

Cress, G. O., B. T. Brady, and G. A. Rowell (1987), Sources of electromagnetic radiation from fracture of rock samples in the laboratory, Geophys. Res. Lett., 14(4), 331-334.

Eccles, D., P.R. Sammonds, and O.C. Clint (2005), Laboratory studies of electrical potential during rock failure, Int. Journ. Rock Mech. Min. Sci., 42, 933-949.

Economides, M. J., and K. G. Nolte (1989), Reservoir stimulation, 2nd ed., Prentice-Hall,/ Englewood Cliffs, N.J.

Enomoto, Y. and H. Hashimoto (1990), Emission of charged particles from indentation fracture of rocks, Nature, 346, 641-643.

Fenoglio, M.A., M.J.S. Johnston, and J.D. Byerlee (1995), Magnetic and electric fields associated with changes in high pore pressure in fault zones: Application to the Loma Prieta ULF emissions, J. Geophys. Res., 100(B7), 12,951-12,958.

Fitterman, D. (1978), Electrokinetic and magnetic anomalies associates with dilatant regions in a layered earth, J. Geophys. Res., 83(B12), 5923-5928.

Gokhberg, M. B., V. A. Morgounov, T. Yoshino, and I. Tomizawa (1982), Experimental measurement of electromagnetic emissions possibly related to earthquakes in Japan, J. Geophys. Res., 87, 7824-7828.

Goldbaum, J., V. Frid, D. Bahat, and A. Rabinovitch (2003), An analysis of complex electromagnetic radiation signals induced by fracture, Meas. Sci. Technol., 14, 1839-1844.

Greenfield, R. J., L. Z. Shuck, and T. W. Keech (1977), Hydraulic fracture mapping using electrical potential measurements, In Situ, 1(2), 147-169.

Grinat, M., J. Sauer, and W. Sudekum (2004), Self potential measurements during hydraulic fracturing of Bunter sandstones, Proc. Near Surface, EAGE, Utrecht, The Netherlands.

Hearst, J. R., P. H. Nelson, and F. L. Paillett (2000), Well logging for physical properties, John WileyInterscience, Hoboken, N. J.

Horn, R. G., and D. T. Smith (1992), Contact electrification and adhesion between dissimilar materials, Science, 256, 362-364. 
International Society for Rock Mechanics (ISRM) (1985), Suggested method for determining point load strength, Int. J. Rock Mech. Min. Sci. and Geomech. Abstr., 22(2), 53-60.

Ishido, T., and H. Mizutani (1981), Experimental and theoretical basis of electrokinetic phenomena in rockwater systems and its applications to geophysics, J. Geophys. Res., 86(B3), 1763-1775.

Johnston, M. J. S., J. D. Byerlee, and D. Lockner (2001), Rapid fluid disruption: a source for self-potential anomalies on volcanoes, J. Geophys. Res., 106(B3), 4327-4335.

Jouniaux, L., and J-P. Pozzi (1995), Streaming potential and permeability of saturated sandstones under triaxial stress: consequences for electrotelluric anomalies prior to earthquakes, J. Geophys. Res., 100(B6), 10,197-10,209.

Kanagy II, S. P., and J. C. Mann (1994), Electrical properties of eolian sand and silt, Earth-Science Reviews, 36, 181-204.

Kawakami, N., and S. Takasugi (1994), SP Monitoring during hydraulic fracturing using the TG-2 well, European Assoc. of Exploration Geophysicists; 56th meeting and technical exhibition, Vienna, Austria.

Leroy, P., and A. Revil (2004), A triple-layer model of the surface electrochemical properties of clay minerals, Journal of Colloid and Interface Science, 270, 371-380.

Lockner, D. A., M. J. S. Johnston, and J. D. Byerlee (1983), A mechanism to explain the generation of earthquake lights, Nature, 302, 28-33.

Lockner, D.A., and J.D. Byerlee (1986), Changes in complex resistivity during creep in granite, Pure Appl. Geophys., 124(4/5), 659-676.

Lorne, B., F. Perrier, and J-P. Avouac (1999a), Streaming potential measurements 1. Properties of the electric double layer, J. Geophys. Res., 104(B8), 17,857-17,877.

Lorne, B., F. Perrier, and J-P. Avouac (1999b), Streaming potential measurements 2. Relationship between electrical and hydraulic flow patterns from rock samples during deformation, J. Geophys. Res., 104(B8), 17,879-17,896.

Manthei, G., J. Eisenblätter, and T. Spies (2000), Acoustic emission in rock mechanics studies, in: Acoustic Emission - Beyond the Millennium, Eds.: T. Kishi et al., 127-144.

Marquis, G., M. Darnet, P. Sailhac, and A. K. Singh (2002), Surface electric variations induced by deep hydraulic stimulation: An example from the Soultz HDR site, Geophys. Res. Lett., 29(14).

Martner, S. T., and N. R. Sparks (1959), The electroseismic effect, Geophyisics, 24(2), 297-308.

Middleton, M. F. (1997), Measurements of streaming potential versus applied pressure for porous rocks, Phys. Chem. Earth, 22(1-2), 81-86.

Miyakoshi, J. (1986), Anomalous time variation of the self-potential in the fractured zone of an active fault preceding the earthquake occurrence, Journ. Geomagn. Geoelectr., 38, 1015-1030.

Mizutani, H., T. Ishido, T. Yokokura, and S. Ohnishi (1976), Electrokinetic phenomena associated with the Matsushiro earthquakes, Geophys. Res. Lett., 3, 364-368.

Moore, J. R., S. D. Glaser, H. F. Morrison, and G. M. Hoversten (2004), The streaming potential of liquid carbon dioxide in Berea sandstone, Geophys. Res. Lett., 31(17), Art. No. L17610.

Morgan, F. D., E. R. Williams, and T. R. Madden (1989), Streaming potential properties of westerly granite with applications, J. Geophys. Res., 94(B9), 12,449-12,461.

Morgan, F., D. (1989), Fundamentals of streaming potentials in geophysics: laboratory methods, Lecture Notes in Earth Science, 27, Detection of Subsurface Flow Phenomena, G.-P. Merkler et al. Eds, 133-143.

Morrison, F. D., R. Fernandez, and R. F. Corwin (1979), Earth resistivity, self potential variations, and earthquakes, a negative result for M=4.0, Geophys. Res. Lett., 6(3), 139-142.

Nitsan, U. (1977), Electromagnetic emission accompanying fracture of quartz-bearing rocks, Geophys. Res. Lett., 4(8), 333-336. 
Nourbehecht, B. (1963), Irreversible thermodynamic effects in inhomogeneous media and their applications in certain geoelectric problems, Ph. D. thesis, Mass. Inst. Technol., Cambridge, MA.

Ogawa, T., K. Oike, and T. Miura (1985), Electromagnetic radiations from rocks, J. Geophys. Res., 90(D4), 6245-6249.

Onsager, L. (1931), Reciprocal relations in irreversible processes, 1, Phys. Rev. 37, 405-426.

Pinettes, P., P. Bernard, F. Cornet, G. Hovhannissian, L. Jouniaux, J.-P. Pozzi, and V. Barthes (2002), On the difficulty of detecting streaming potentials generated at depth, Pure Appl. Geophys., 159, 2629-2657.

Pride, S. R., and F. D. Morgan (1991), Electrokinetic dissipation induced by seismic waves, Geophysics, 56, 914-925.

Pride, S. R. (1994), Governing equations for the coupled electromagnetics and acoustics of porous media, Phys. Rev. B, 50(21), 15,678-15,696.

Pritchett, J. W., and T. Ishido (2005), Hydrofracture characterization using downhole electrical monitoring, Proc. World Geothermal Congress, Antalya, Turkey.

Ren, L., W. Qu, and L. Dongqing (2001), Interfacial electrokinetic effects on liquid flow in microchannels, Int. J. Heat Mass Transfer, 44, 3125-3134.

Reppert, P. M. and F. D. Morgan (2003), Temperature-dependant streaming potentials: 2. laboratory, J. Geophys. Res., 108(B11), doi:10.1029/2002JB001755.

Revil, A., H. Schwaeger, L. M. Cathles, and P. Manhardt (1999), Streaming potential in porous media 2. Theory and applications to geothermal systems, J. Geophys. Res., 104(B9), 20,033-20,048.

Revil, A. and M. Pessel (2002), Electroosmotic flow and the validity of the classical Darcy equation in silty shales, Geophys. Res. Lett., 29(9), doi:10.1029/2001GL013480.

Revil, A., G. Saracco, and P. Labazuy (2003), The volcano-electric effect, J. Geophys. Res., 108(B5), doi:10.1029/2002JB001835.

Scholz, C., L. Sykes, and Y. Aggarwal (1973), Earthquake prediction: A physical basis, Science, 181, 803810 .

Sharma, M. M., J. F. Kuo, and T. F. Yen (1987), Further investigation of the surface charge properties of oxide surfaces in oil-bearing sands and sandstones, Journal of Colloid and Interface Science, 115, 9-16.

Shlyapobersky, J., J. W. Dudley, and A. Chudnovsky (1994), Laboratory investigation of fracture processes in hydraulic fracturing, Quarterly Report for The Gas Research Institute, Contract No 5093-221-2611, September.

Smoluchowski, M. (1903) Contribution à la théorie de l'endosmose électrique et de quelques phenomènes corrélatifs, Bulletin International de l'Academie des Sciences de Cracovie, 8, 182-200.

Tosha, T., N. Matsushima, and T. Ishido (2003), Zeta potential measured for an intact granite sample at temperatures to $200^{\circ} \mathrm{C}$, Geophys. Res. Lett., 30(6), doi:10.1029/2002GL016608.

Tuck, G. J., F.D. Stacey, and J. Starkey (1977), A search for the piezoelectric effect in quartz-bearing rocks, Tectonophysics, 39, T7-T11.

Ushijima, K., H. Mizunaga, and T. Tanaka (1999), Reservoir monitoring by a 4-D electrical technique, The Leading Edge, 18, 1422-1424,

Varotsos, P., K. Sarlis, M. Eftaxias, N. Lazardiou, J. Bogris, J. Makris, A. Abdulla, and P. Kapiris (1999), Prediction of the 6.6 Grevena-Kozani earthquake of May 13, 1995, Phys. Chem. Earth, 24, 115-121.

Watillon, A. and R. de Backer (1970), Potentiel d'écoulement, courant d'écoulement et conductance de surface à l'interface eau-verre, J. Electroanal. Chem., Interfacial Electrochem., 25, 181-196.

Wang, C., P. Sundaram, and R. Goodman (1978), Electrical resistivity changes in rocks during frictional sliding and fracture, Pure App. Geophys., 116, 717-731. 
Warwick, J. W., C. Stoker, and T. R. Meyer (1982) Radio emission associated with rock fracture: possible application to the great Chilean earthquake of May 22, 1960, J. Geophys. Res., 87, 2851-2859.

Wills, P., D. DeMartini, H. Vinegar, J. Shlyapobersky, W. Deeg, J. Woerpels, J. Fix, G. Sorrells, and R. Adair (1992), Active and passive imaging of hydraulic fractures: The Leading Edge, 11(7), 15-22.

Wurmstich, B. (1995), 3D self-consistent modeling of streaming potential responses; theory and feasibility of applications in earth sciences, Doctoral Thesis, Texas A\&M University, College Station, TX, United States.

Yoshida, S., M. Uyeshima, and M. Nakatani (1997), Electric potential changes associated with slip failure of granite: preseismic and coseismic signals, J. Geophys. Res., 102, 14,883-14,897.

Yoshida, S., O. Clint, and P. Sammonds (1998), Electric potential changes prior to shear fracture in dry and saturated rocks, Geophys. Res. Lett., 25, 1577-1580.

Yoshida, S. (2001), Convection current generated prior to rupture in saturated rocks, J. Geophys. Res., 106(B2), 2103-2120.

Zoback, M. D., and J. D. Byerlee (1975), The effect of microcrack dilatancy on the permeability of Westerly granite, J. Geophys. Res., 80(5), 752-755.

Zhu, Z., M. W. Haartsen, and M. N. Toksöz (1999), Experimental studies of electrokinetic conversions in fluid-saturated borehole models, Geophysics, 64(5), 1349-1356. 
Table 1: Summary of experiments performed to investigate the self-potential response during hydraulic fracturing of intact granite specimens. Testing to determine the hydroelectric transport properties of Sierra granite is not included in this table, see Section 4.

\begin{tabular}{|c|c|c|c|c|c|}
\hline Test Name & Test Conditions & $\begin{array}{c}\text { Response } \\
\text { Monitored }\end{array}$ & Rock Type & Sample Size & $\begin{array}{c}\text { Number of } \\
\text { Samples }\end{array}$ \\
\hline \multirow[t]{3}{*}{$\begin{array}{l}\text { Unconfined } \\
\text { Cores }\end{array}$} & $\begin{array}{l}\text { Constant flow rate } \\
\text { hydraulic fracturing } \\
\text { with } 0.001 \mathrm{M} \mathrm{NaCl}\end{array}$ & SP & $\begin{array}{l}\text { Sierra } \\
\text { granite }\end{array}$ & $\begin{array}{l}102 \mathrm{~mm} \text { long, } \\
57 \mathrm{~mm} \text { diam. core }\end{array}$ & $\begin{array}{c}7 \\
(\mathrm{SG}-2- \\
\text { SG-8) }\end{array}$ \\
\hline & $\begin{array}{l}\text { Constant flow rate } \\
\text { hydraulic fracturing } \\
\text { with } 0.001 \mathrm{M} \mathrm{NaCl}\end{array}$ & Resistivity & $\begin{array}{l}\text { Sierra } \\
\text { granite }\end{array}$ & $\begin{array}{l}102 \mathrm{~mm} \text { long, } \\
57 \mathrm{~mm} \text { diam. core }\end{array}$ & 3 \\
\hline & $\begin{array}{l}\text { Constant flow rate } \\
\text { hydraulic fracturing } \\
\text { with liquid } \mathrm{CO}_{2}\end{array}$ & SP & $\begin{array}{l}\text { Westerly } \\
\text { granite }\end{array}$ & $\begin{array}{l}102 \mathrm{~mm} \text { long, } \\
57 \mathrm{~mm} \text { diam. core }\end{array}$ & 1 \\
\hline $\begin{array}{l}\text { Triaxially } \\
\text { Confined } \\
\text { Cubes }\end{array}$ & $\begin{array}{l}\text { Constant flow rate } \\
\text { hydraulic fracturing } \\
\text { with } 0.001 \mathrm{M} \mathrm{NaCl}\end{array}$ & $\mathrm{SP}$ and $\mathrm{AE}$ & $\begin{array}{l}\text { Sierra } \\
\text { granite }\end{array}$ & $260 \mathrm{~mm}$ cube & 2 \\
\hline $\begin{array}{l}\text { Point Load } \\
\text { Testing }\end{array}$ & $\begin{array}{l}\text { Point load tensile } \\
\text { fracture of wet } \\
\text { specimens }\end{array}$ & $\mathrm{SP}$ and $\mathrm{AE}$ & $\begin{array}{l}\text { Sierra \& } \\
\text { Westerly } \\
\text { granite, } \\
\text { limestone }\end{array}$ & $\begin{array}{c}50 \mathrm{~mm} \text { long, } \\
50 \mathrm{~mm} \text { diam. core }\end{array}$ & 21 \\
\hline
\end{tabular}

Table 2: Sierra granite material properties (values are measured unless otherwise noted).

\begin{tabular}{lll}
\hline Porosity $(\phi)$ & 0.009 & $(0.9 \%)$ \\
Permeability at low pore pressure $\left(k_{o}\right)$ & $1.0 \times 10^{-18} \mathrm{~m}^{2}$ & \\
Bulk conductivity $\left(\sigma_{b}\right)$ with $0.001 \mathrm{M} \mathrm{NaCl}$ & $1.25 \times 10^{-4} \mathrm{~S} / \mathrm{m}$ & $(8000 \Omega-\mathrm{m})$ \\
Bulk conductivity $\left(\sigma_{b}\right)$ with $0.22 \mathrm{M} \mathrm{NaCl}$ & $2.0 \times 10^{-3} \mathrm{~S} / \mathrm{m}$ & $(500 \Omega-\mathrm{m})$ \\
Surface conductivity $\left(\sigma_{s}\right)($ calculated $)$ & $1.1 \times 10^{-4} \mathrm{~S} / \mathrm{m}$ & $(9000 \Omega-\mathrm{m})$ \\
Formation Factor $(F)$ with $0.001 \mathrm{M} \mathrm{NaCl}$ & 120 & \\
Formation Factor $\left(F_{o}\right)$ with $0.220 \mathrm{M} \mathrm{NaCl}$ & 1000 & \\
Electrical Tortuosity $\left(\tau_{e}\right)($ calculated $)$ & 3 \\
Hydraulic radius $(m)($ calculated $)$ & $1.5 \times 10^{-7} \mathrm{~m}$ & \\
Coupling Coefficient $(C c)$ with $0.001 \mathrm{M} \mathrm{NaCl}$ & $-200 \mathrm{mV} / \mathrm{MPa}$ & $\left(-2 \times 10^{-7} \mathrm{~V} / \mathrm{Pa}\right)$ \\
Zeta potential $(\zeta)$ with $0.001 \mathrm{M} \mathrm{NaCl}($ calculated) & $-35 \mathrm{mV}$ & \\
\hline
\end{tabular}




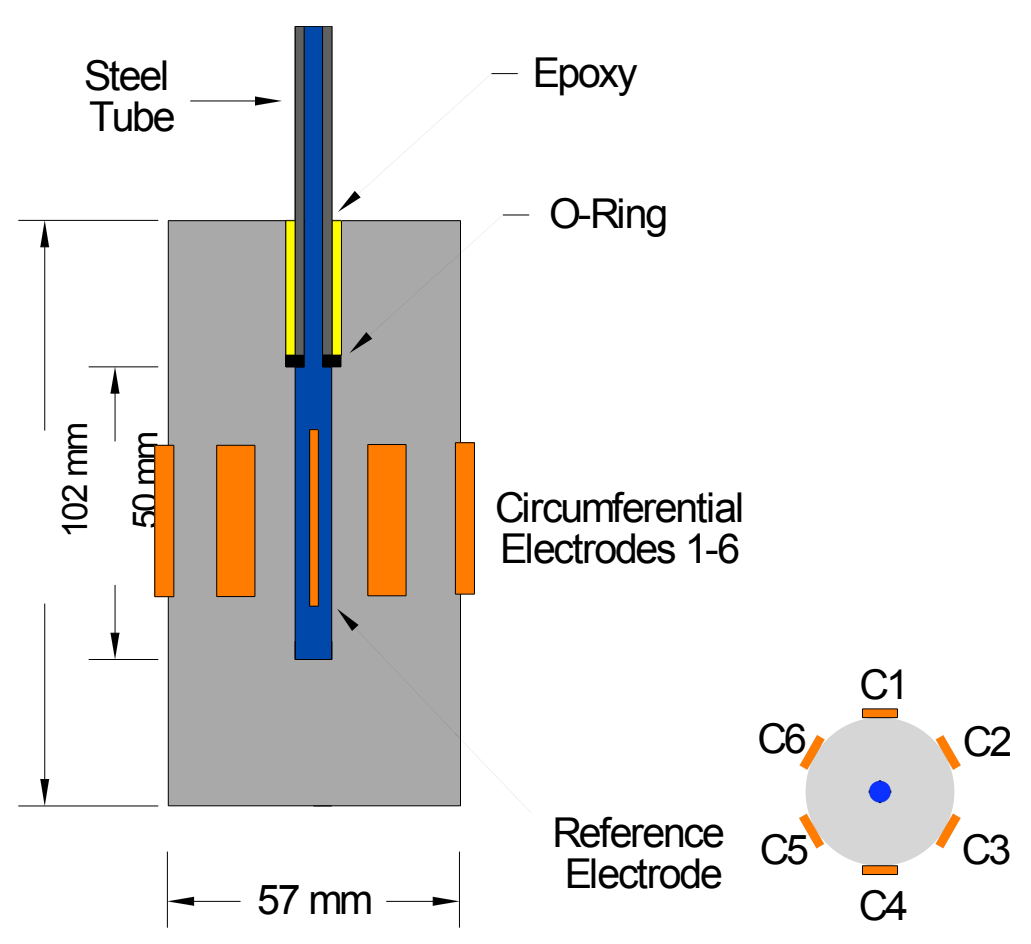

Figure 1: Schematic of Sierra granite core specimens for unconfined hydraulic fracturing.

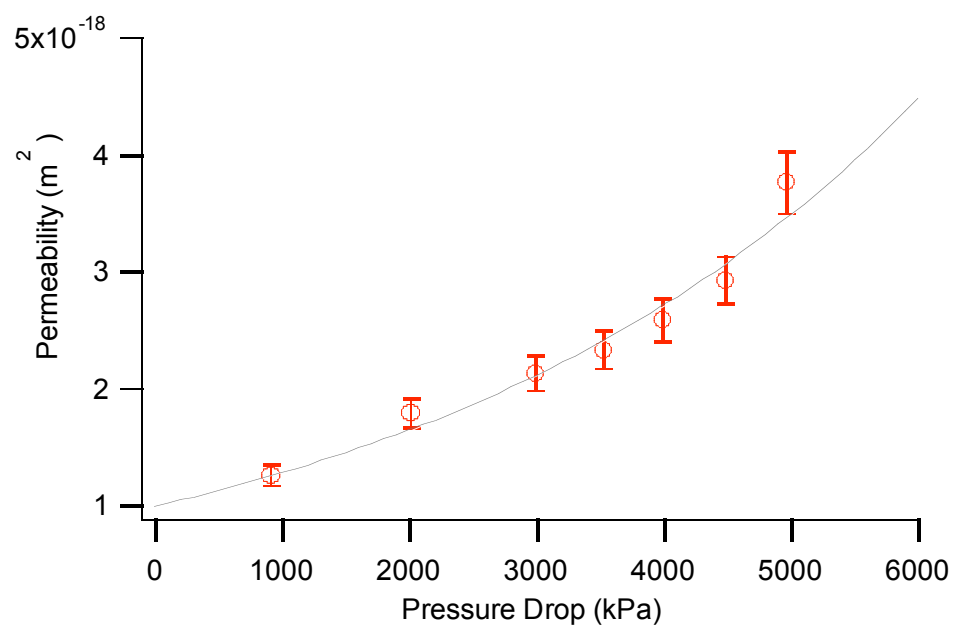

Figure 2: Permeability of Sierra granite measured as a function of pressure drop across the $25.4 \mathrm{~mm}$ cylinder radius. At high fluid pressure gradients the permeability increases by as much as $275 \%$ due to dilatancy of micro-cracks. The permeability at zero pressure drop is extrapolated to be $1.0 \times 10^{-18} \mathrm{~m}^{2}$. 

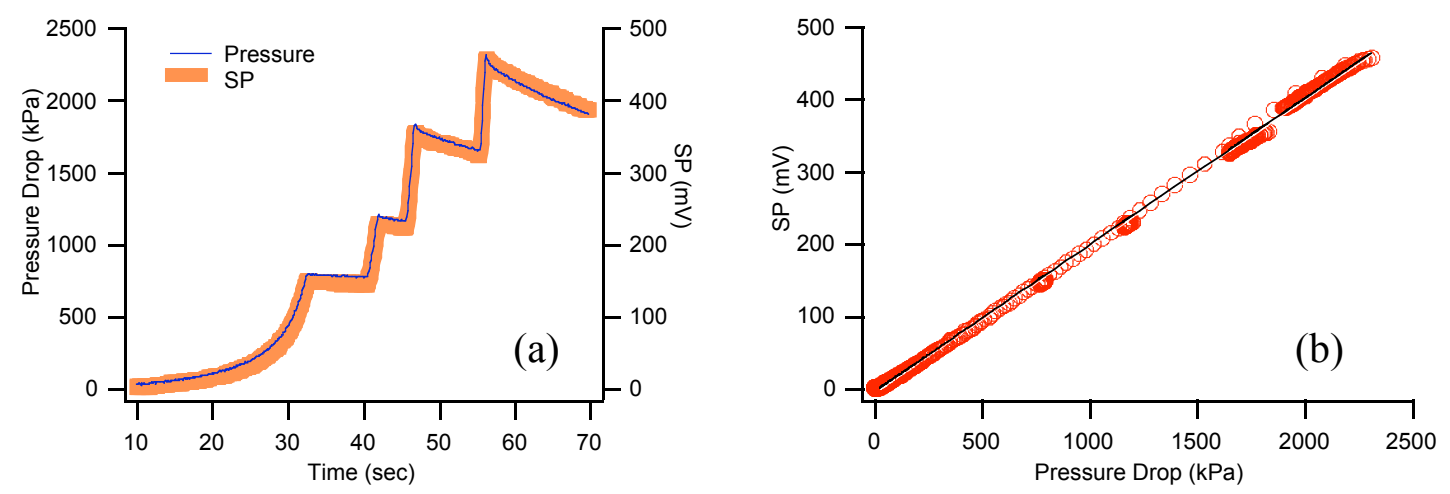

Figure 3: a) Radial fluid pressure drop and SP response for low-pressure testing of a Sierra granite core prior to hydraulic fracturing, b) Linear variation of SP with pressure drop indicates a constant $\mathrm{Cc}$ of $-200 \mathrm{mV} / \mathrm{MPa}$ for pressure drops $<\sim 2 \mathrm{MPa}$.
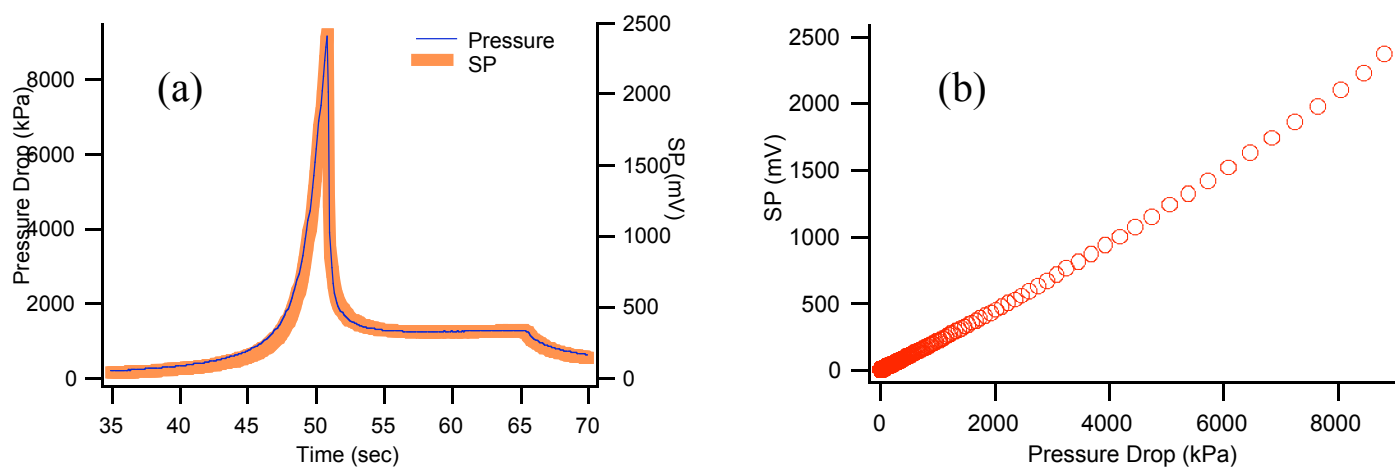

Figure 4: a) Radial fluid pressure drop and SP response during hydraulic fracturing of a Sierra granite core, b) Variation of SP with pressure drop for pressures preceding fracture initiation. Above $\sim 2 \mathrm{MPa}$ the variation is non-linear indicating that the magnitude of the $\mathrm{Cc}$ increases with increasing pressure drop. 


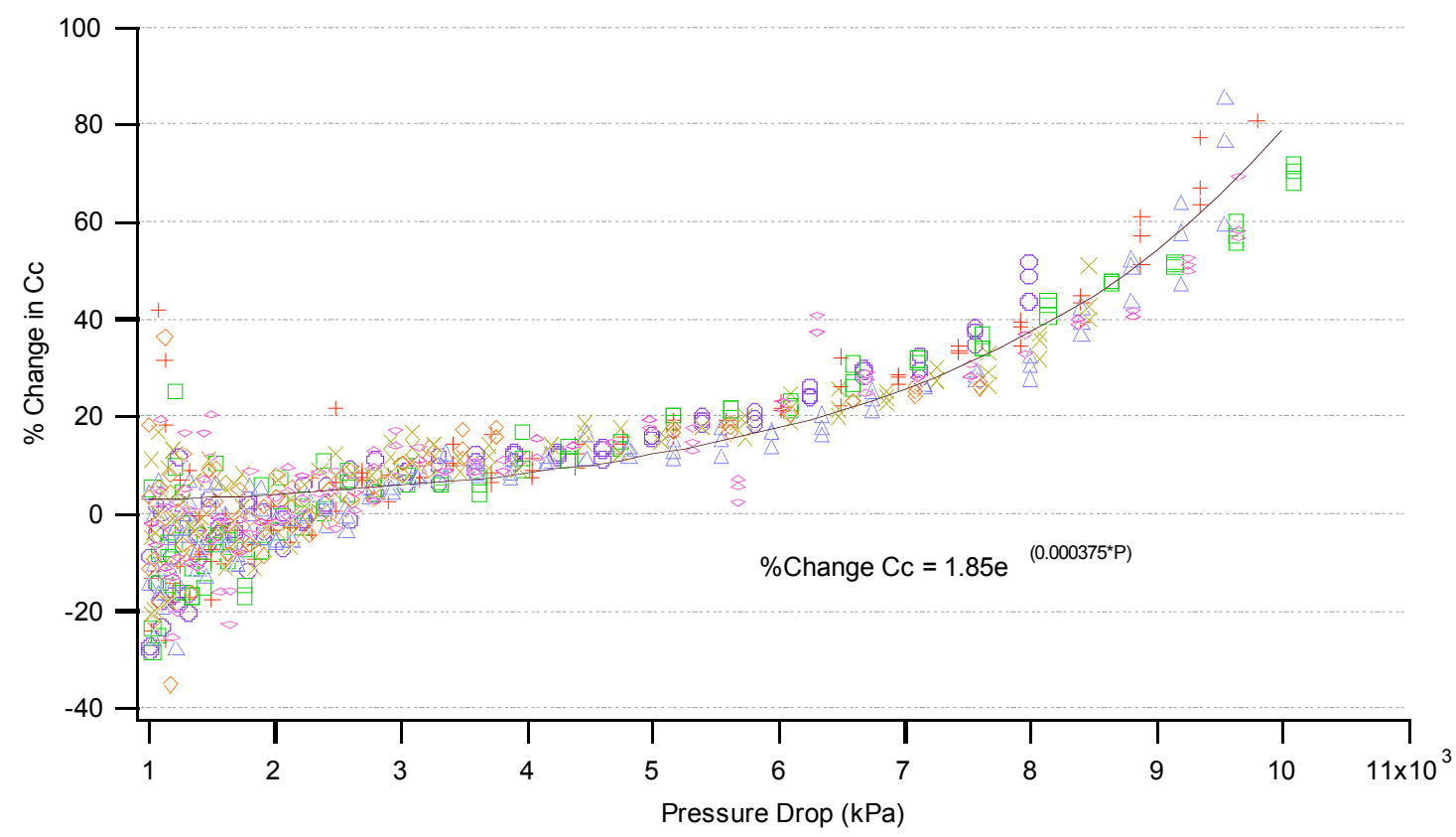

Figure 5: Variation of the magnitude of the Cc with radial pressure drop for 7 samples of Sierra granite. The $|\mathrm{Cc}|$ increases exponentially with pressure drop, up to $80 \%$ just prior to hydraulic fracturing. The best fit exponential trend to all data is shown as a solid line along with its numerical expression. (Specimen legend: SG2-plus, SG3-circle, SG4square, SG5-triangle, SG6-diamond, SG7-oval, SG8-cross) 

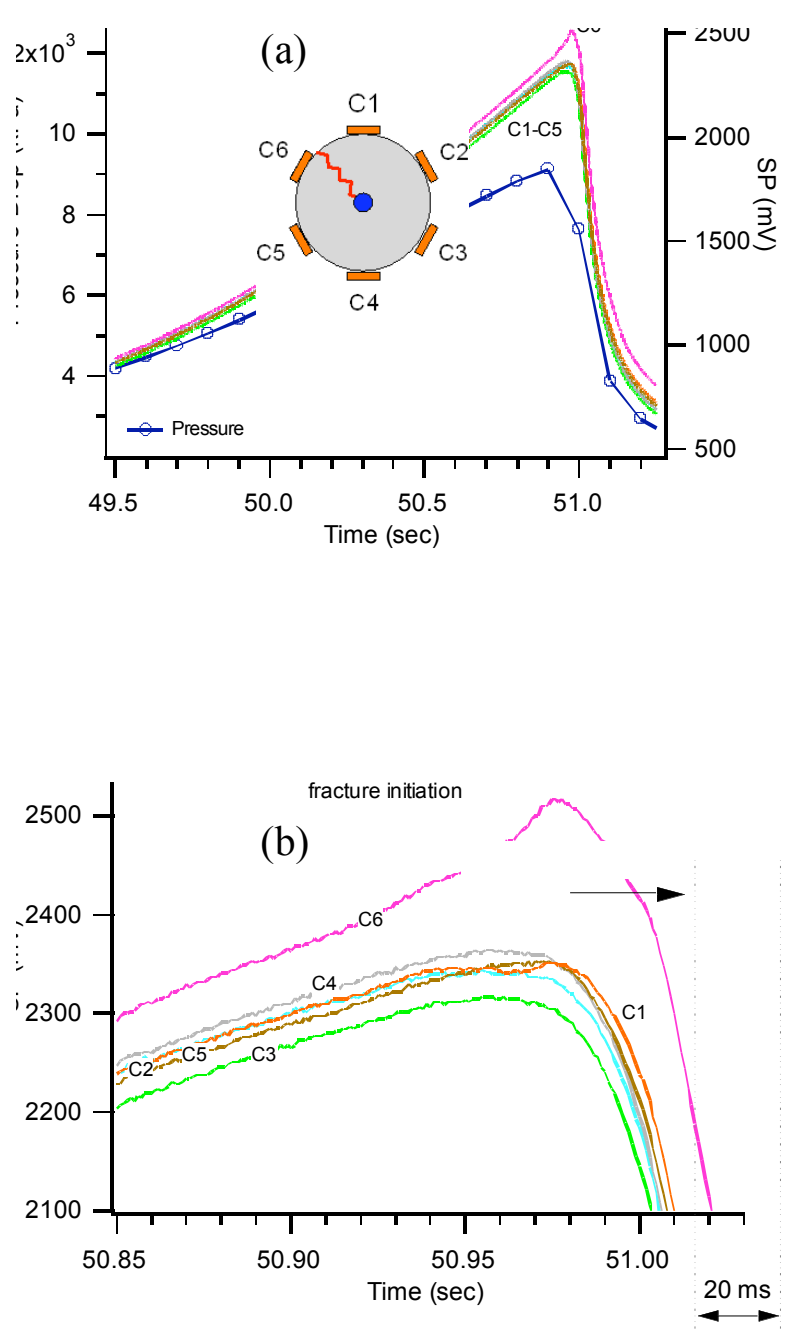

Figure 6: (a) Radial fluid pressure drop and SP response for all 6 circumferential electrodes during hydraulic fracturing of sample SG-8. The SP prior to failure at electrode C6 is slightly greater, indicating increased injectate infiltration in this area. The fracture geometry noted after testing is shown by the inset to be single-lobed towards C6. (b) Expanding the SP record for times about failure, a SP spike can be seen on C6 peaking $20 \mathrm{~ms}$ after hydraulic fracturing, which is roughly the time required for injectate to reach the sample edge. This spike results from injectate movement into the new fracture void space. 


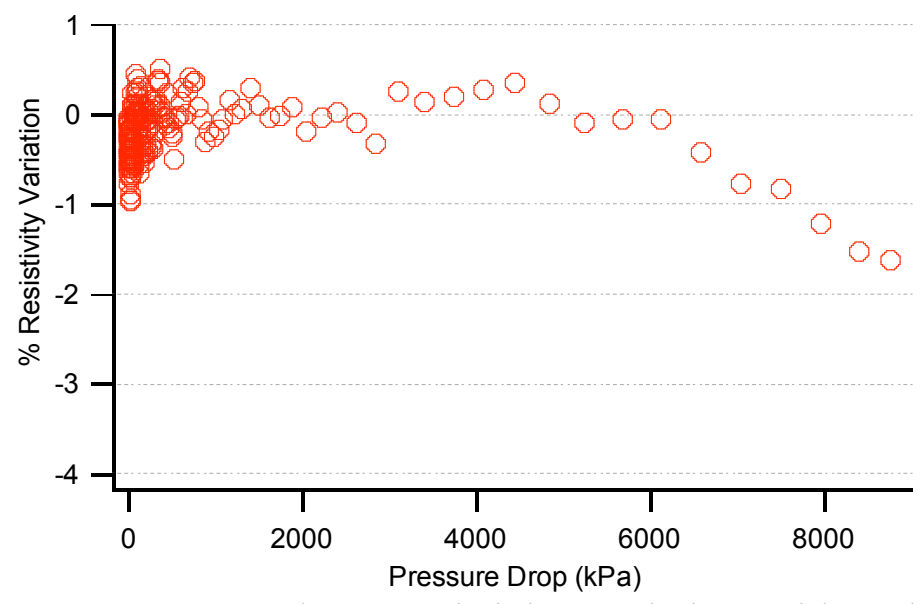

Figure 7: Specimen resistivity variation with radial fluid pressure drop prior to hydraulic fracturing of Sierra granite. As pressure increases, the specimen resistivity decreases by up to $2 \%$ immediately preceding rupture due to injectate infiltration into dilatant micro-porosity. After fracturing, the bulk specimen resistivity decreased by about 35\% (not shown). 


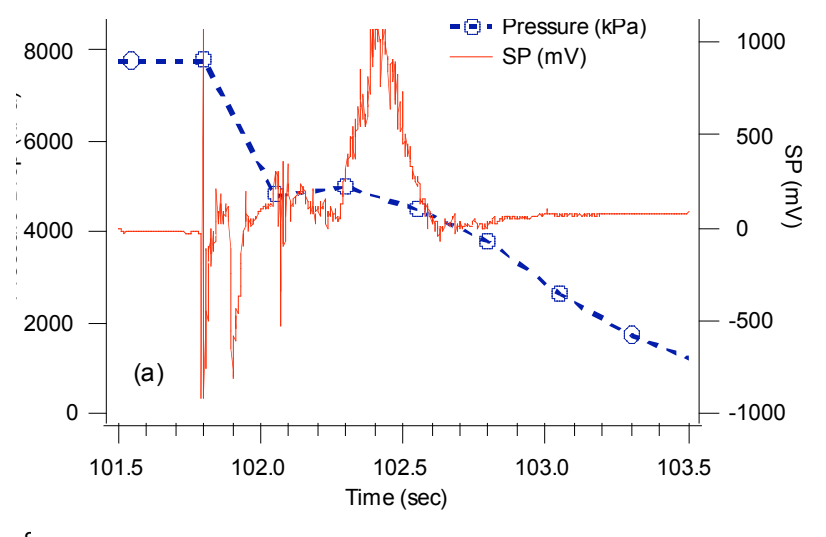

$\varepsilon$

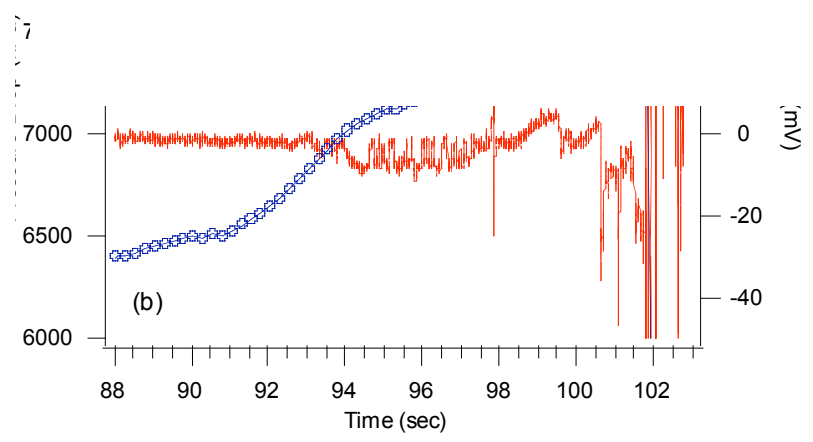

Figure 8: Hydraulic fracturing of a unconfined Westerly granite core specimen with liquid $\mathrm{CO}_{2}$. (a) In the absence of electrokinetic effects, the brief negative SP spikes may be caused by contact electrification, while the broad positive response may result from rapid fluid disruption (RFD) as the liquid $\mathrm{CO}_{2}$ changes phase to gas. (b) Extending the timeline from (a) above, minor failures were noted at 90, 94, and $98 \mathrm{~s}$ in the pressure record, and gas could be heard escaping the sample during this time. The lack of substantial SP response during these events suggests that electrokinetic coupling is the dominant mechanism generating the SP response during hydraulic fracturing with water. 


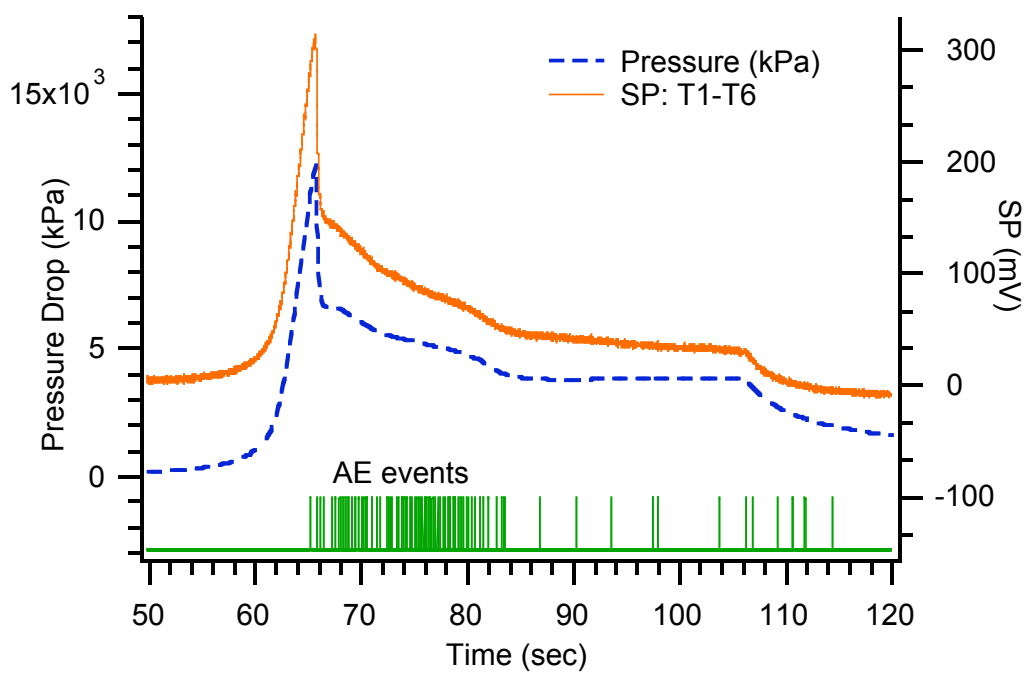

Figure 9: Pressure drop, recorded time of acoustic emission (AE) events, and raw SP data for hydraulic fracturing of a $260 \mathrm{~mm}$ Sierra granite cube (electrodes T1-T6) in a true-triaxial stress state. Variations of individual SP electrodes are not visible at this scale. The failure event is noted by SP and pressure spikes and the onset of AE events. Crack growth continued for $\sim 18 \mathrm{~s}$ following initial fracturing until reaching the sample edge. The overall SP response closely mimics the fluid pressure drop suggesting an electrokinetic source mechanism.

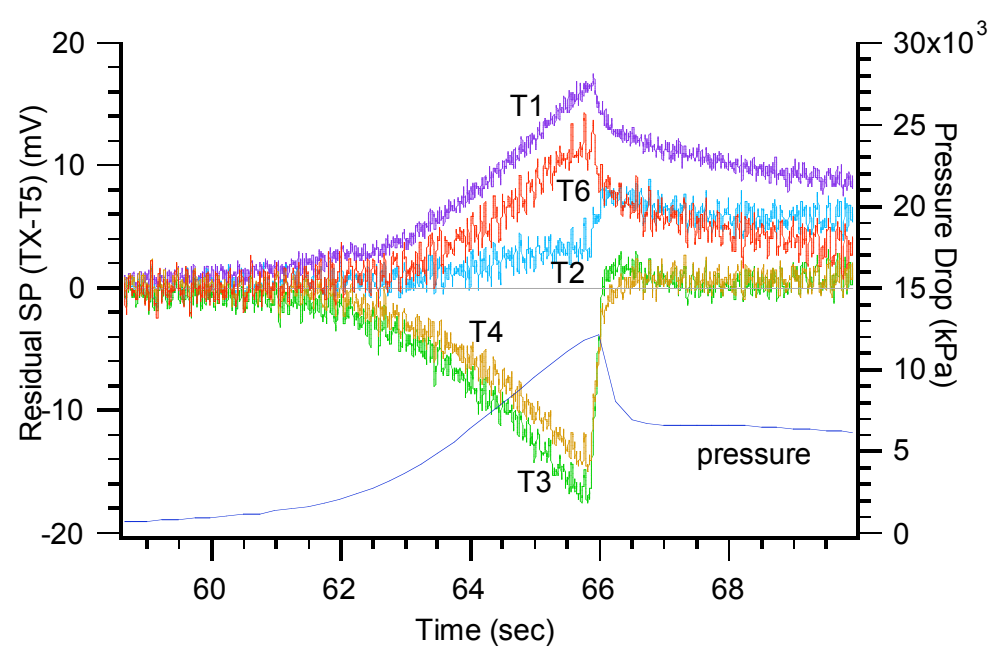

Figure 10: Residual SP for electrodes T1-T6. The hydraulic fracture propagated in the direction of electrodes $\mathrm{T} 1$ and $\mathrm{T} 6$, while electrodes $\mathrm{T} 3$ and $\mathrm{T} 4$ were opposite the direction of fracture propagation. Residual SP traces were created by subtracting the time series of electrode T5 (which was nearest the average value) from each measuring electrode to clarify the spatial SP response. 


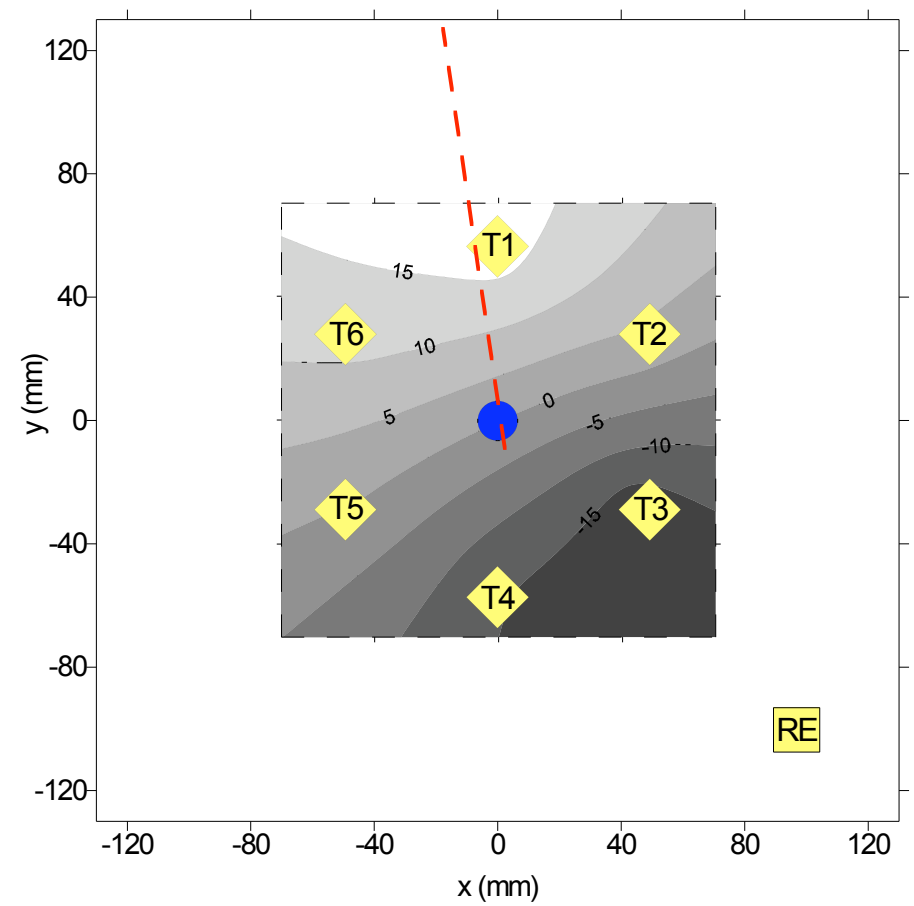

Figure 11: Spatial view of the residual SP response on the top surface of the Sierra granite cube (electrodes T1-T6) at the time of hydraulic fracture initiation. A directional response is evident from the residual SP anomaly and is characterized by a positive SP in the direction of fracture propagation and fluid flow. The crack direction was determined by examination after testing, and the trace is sketched (dashed line). The injection point is circled in the sample center, and the reference electrode is denoted "RE."

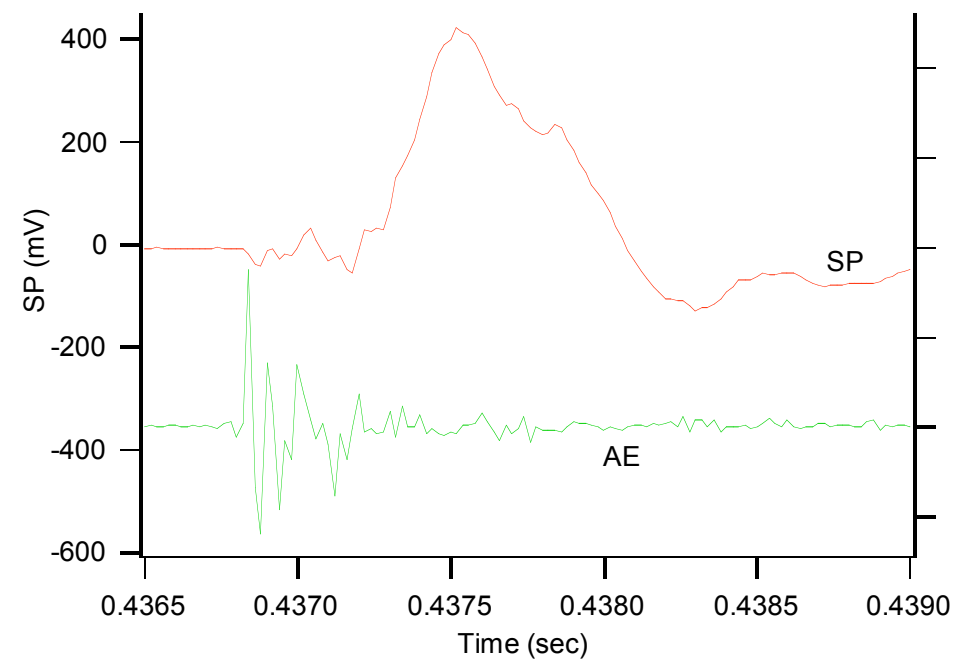

Figure 12: Representative SP (measured across the fracture) and acoustic emission (AE) response (arbitrary units) during specimen rupture in point load testing of wet Westerly granite. Over all testing, the magnitude of the SP spike observed at fracture initiation ranged from 150-400 $\mathrm{mV}$ (both positive and negative spikes were observed) and decayed within approximately $500 \mu \mathrm{s}$. 


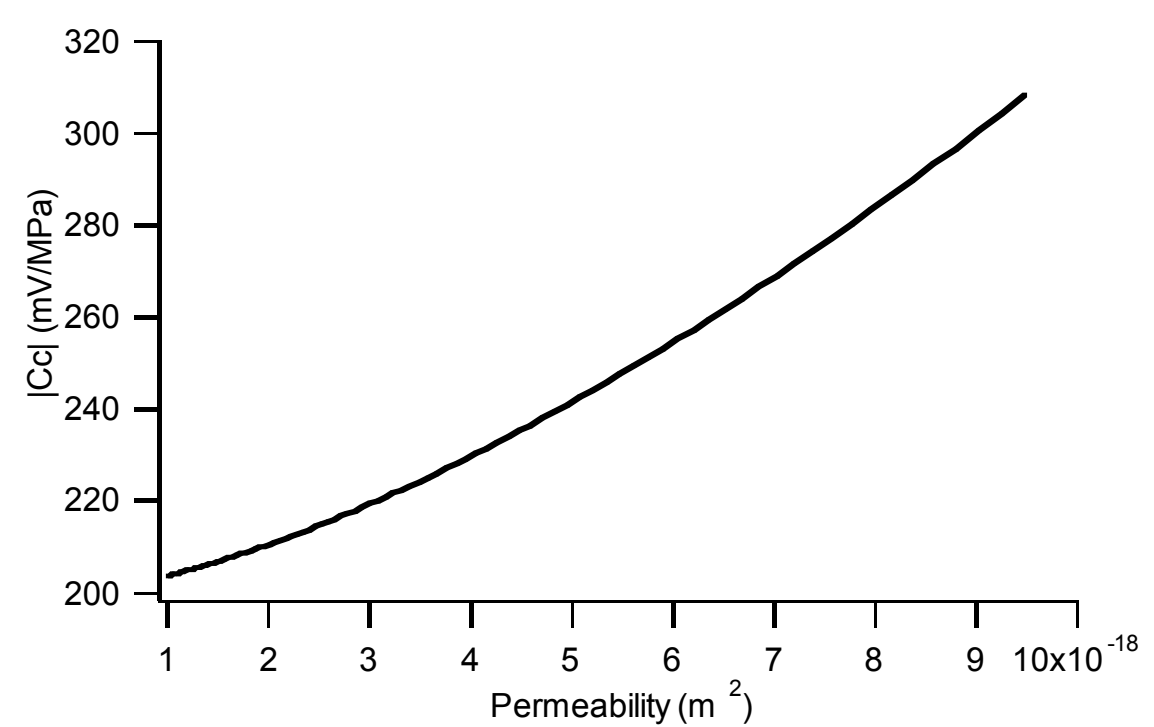

Figure 13: Variation of the magnitude of the Cc with permeability found by combining Equations (9) and (14). The $|\mathrm{Cc}|$ increases as $k^{1.5}$ (see Equation 15). 